\title{
Resiliency in Youth Who Have Been Exposed to Violence
}

Nancy Ghali

Cleveland State University

Follow this and additional works at: https://engagedscholarship.csuohio.edu/etdarchive

Part of the Education Commons

How does access to this work benefit you? Let us know!

\section{Recommended Citation}

Ghali, Nancy, "Resiliency in Youth Who Have Been Exposed to Violence" (2012). ETD Archive. 107. https://engagedscholarship.csuohio.edu/etdarchive/107

This Dissertation is brought to you for free and open access by EngagedScholarship@CSU. It has been accepted for inclusion in ETD Archive by an authorized administrator of EngagedScholarship@CSU. For more information, please contact library.es@csuohio.edu. 


\title{
RESILIENCY IN YOUTH WHO HAVE BEEN EXPOSED TO VIOLENCE NANCY GHALI
}

\author{
Bachelor of Arts in Psychology \\ Wittenberg University \\ June 1993 \\ Master of Arts in Community Counseling \\ John Carroll University \\ January 2000
}

submitted in partial fulfillment of requirement for the degree

DOCTOR OF PHILOSOPHY IN URBAN EDUCATION

at the

CLEVELAND STATE UNIVERSITY

August 2012 


\section{Dedication}

This research project is dedicated to my father, Zak, who provided me with the foundation to value education and also to my son, Shane, who provides me with the motivation to make a difference in the world around me. 


\section{Acknowledgments}

I would like to acknowledge Dr. Schultheiss for all of her guidance and support during the duration of this study. She offered me support and understanding during the difficult times and pushed me to keep going when my motivation was depleted. Her guidance helped make the process of completing my dissertation very smooth. Her passion for teaching is evident and greatly appreciated. I would also like to acknowledge Dr. Welfel for her encouragement and constant cheerful disposition. Thank you for cheering me on through internship and the completion of my dissertation. I am thankful to rest of my dissertation committee including Dr. Stead, Dr. Hollinger, and Dr. PereraDiltz for their time and suggestions in creating a more polished finished project.

I am forever grateful to Brenda and Mike Simpson for loving and nurturing my son while I was in class. Without their support I would not have been able to complete my studies. Thank you for being such a constant and wonderful influence in Shane's life.

Finally, I would like to acknowledge my father who taught me to value education and always encouraged me to pursue my goals. He raised me to be confident, independent, and caring and I am grateful for the person I have become because of him. 
This dissertation has been approved for the Office of Doctoral Studies, College of Education and Human Services and the College of Graduate Studies by

Donna Schultheiss, Chairperson $05 / 29 / 2012$ Counseling, Administration, Supervision, and Adult Learning Graham Stead, Methodologist $5 / 29 / 2012$

Curriculum and Foundations

Elizabeth Welfel, Member $5 / 29 / 2012$

Counseling, Administration, Supervision, and Adult Learning

Dilani Perera-Diltz, Member $5 / 29 / 2012$

Counseling, Administration, Supervision, and Adult Learning

Psychology 


\title{
RESILIENCY IN YOUTH WHO HAVE BEEN EXPOSED TO VIOLENCE
}

\section{NANCY GHALI}

\begin{abstract}
Youth who have been victims of crime or are exposed to community violence are at high risk for developing conduct problems. However, not all youth who have been exposed to violence develop behavioral problems. The purpose of this study is to explore the relationship between resiliency factors such as sense of mastery, relatedness, emotional reactivity, relatedness to parents, friends, and teachers, and conduct problems in youth who have been exposed to violence in a general population of high school students. The independent variables are measured using the Children's Report of Exposure to Violence, the Resiliency Scales for Children and Adolescents, and the Hemmingway Measure of Adolescent Connectedness. The Youth Self Report was utilized to measure the dependent variables in this study. A canonical correlation was used to analyze the data. The full canonical model was significant and accounted for $37 \%$ of the variance between canonical composites with two canonical roots emerging. The first root accounted for $79 \%$ of the overall variance between the canonical composites. Youth who have high exposure to violence and a high level of emotional reativity and a low connection to parents and teachers reported more aggressive behavior and rule breaking behavior. The second canonical root accounted for $21 \%$ of the overall variance between canonical composites. Youth who reported having a sense of connectedness to others also reported low emotional reactivity and aggressive behaviors but to a lesser extent.
\end{abstract}




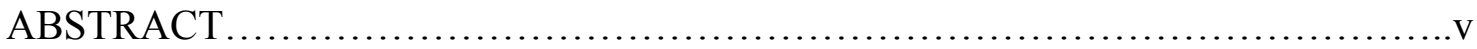

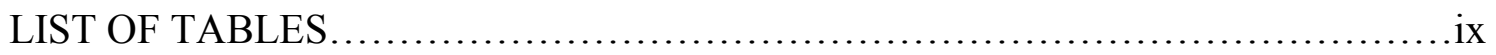

\section{CHAPTER}

\section{STATEMENT OF THE PROBLEM}

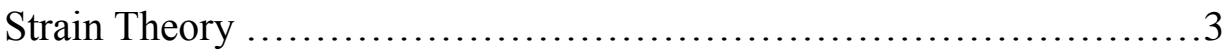

Risk Factors......................................................

Resiliency Factors...........................................9

Significance of the Study ......................................14

\section{REVIEW OF THE LITERATURE}

Risk Factors................................................15

Exposure to Violence........................................ 17

Resiliency Factors.........................................19

Sense of Mastery............................................21

Relatedness..................................................22

Emotional Reactivity........................................25

III. METHOD

Participants..................................................27

Hypothesis..................................................28

Measures....................................................28

Demographic Questionnaire.....................................28

Children's Report of Exposure to Violence.........................29

The Resiliency Scales for Children and Adolescents..................31 
The Hemmingway Measure of Adolescent Connectedness................34

The Child Behavior Checklist - Youth Self Report.....................38

Procedures........................................................41

Data Analysis..................................................42

IV. RESULTS

Preliminary Analysis..........................................43

Multivariate Analysis...........................................44

\section{DISCUSSION}

Overview...................................................47

Summary.....................................................49

Limitations of the Study .....................................52

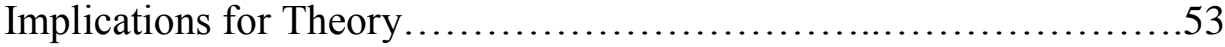

Implications for Practice......................................54

Implications for Research....................................59

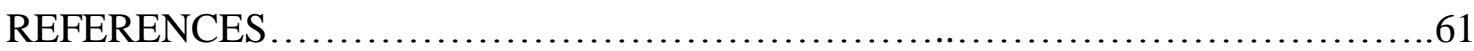

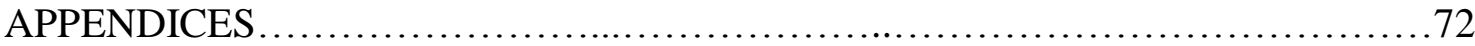

A. Internal Review Board Approval Letter................................73

B. Informed Consent Form........................................ 75

C. Assent Form .......................................................... 77

D. Demographic Questionnaire...................................... 79

E. Child Behavior Checklist-Youth Self Report..........................81

F. Hemmingway Measure of Adolescent Connectedness.....................82 
G. Children's Report of Exposure to Violence-Revised......................84

H. Resiliency Scales for Children and Adolescents.............................90 


\section{List of Tables}

Table

I. Means, standard deviations, Pearson product-moment correlation coefficients, and reliability coefficients of rule breaking behavior, aggressive behavior, exposure to violence, resiliency, and

connectedness subscales.....................................44

II. Structure coefficients for significant canonical roots..................46 


\section{Chapter I}

\section{Statement of the Problem}

Juvenile delinquency is a major concern for many communities. An estimated 2.2 million juveniles under the age of 18 were arrested in the United States in 2006 (Snyder, 2007). Juveniles accounted for 17 percent of all violent arrests and 26 percent of all property crime in the United States during that year (Snyder, 2007). According to Farrington (2005) juveniles who are involved in illegal acts such as stealing and vandalism, and demonstrated conduct problems such as resistance to authority and physical aggression, were more likely to exhibit antisocial behaviors such as crime, violence, excessive drinking and drug-taking, a poor employment record, marital breakups, child neglect, reckless driving and failure to pay debts as adults. Being exposed to adverse conditions increases the likelihood that a juvenile will experience strain and therefore engage in delinquent behavior (Agnew, 1985). Agnew (1985) developed Strain Theory to explain why some youth become involved in delinquent behavior.

The prevalence and related negative effects of juvenile delinquency has generated a great deal of interest in researching this population (Farington, 2005; Hanlon, et al., 2004; Hart, O’Toole, Price-Sharps, \& Shaffer, 2007) in an effort to reduce delinquency and recidivism rates. Unfortunately, many of the attempts to treat chronic delinquency 
and childhood anti-social behavior have been shown to be ineffective (Kazdin, 1987) suggesting that prevention may be more effective than treatment in reducing juvenile delinquency rates (Yoshikawa, 1994). Youth who engage in pre-delinquent activity at an early age are more likely to engage in later delinquent activity (Hanlon et al., 2004).

Few studies of youth who have been exposed to violence are based on a representative sample of school or community populations of adolescents (Ozer \& Weinstein, 2004). Previous research has often focused on a clinical population. While understanding how exposure to violence leads to conduct problems in a clinical population is important, it is equally important to understand how some youth who have been exposed to violence manage to avoid exhibiting conduct problems. Although gang members were found to engage in violent crimes at a higher rate than non-gang involved youth (Howell, 1998), they will not be the focus of this study. Instead, this study will examine the resiliency of youth in a general population. The findings from studying a general population would be more readily generalized than findings from research with a sample of clinically referred youth (Ozer \& Weinstein, 2004). A better understanding of the resiliency factors that protect youth from the harmful effects of being exposed to violence would provide crucial information to create effective prevention and intervention programs.

The current study expanded the current literature by examining the resiliency factors, sense of mastery, relatedness, and emotional reactivity of youth in a general population. The purpose of this study is to explore the relationship between resiliency factors such as sense of mastery, relatedness, and emotional reactivity, and conduct problems in youth who have been exposed to violence in a general population. By 
exploring these resiliency factors in youth who have been exposed to violence, we gain vital information that can be generalized to at risk youth in a preventative form that may keep them from engaging in delinquent behaviors. Several theories have been developed to explain why juveniles engage in delinquent behavior (Agnew, 1985; Hirschi, 1969; Sutherland, 1924).

One theory explaining the causes of delinquency is social control theory (Hirschi, 1969) which frames delinquency as resulting from youth having little or no ties to conventional order such as schools or families to prevent them from engaging in delinquent behavior. Youth who have strong attachments to their parents and social ties to their community are less likely to engage in delinquent behavior (Hirschi, 1969). Another theory which attempts to explain the causes of juvenile delinquency is the differential association theory (Sutherland, 1924). According to Sutherland (1924) youth become delinquent after associating with older peers who engage in criminal behavior. While both of these theories explain delinquent behavior within the context of the youth's environment, they do not take into consideration the effects of adverse situations that the youth are exposed to such as exposure to violence. This study will focus on Strain Theory as it frames delinquency as a reaction to risk factors which some youth are exposed to.

\section{Strain Theory}

According to Agnew's Strain Theory, youth become involved in delinquent behavior out of anger and frustration caused by the inability to obtain financial success through legitimate means (Agnew, 1985). This lack of financial success then leads to frustration and anger or "strain." The strain may then lead to youth engaging in delinquent behavior to gain the material items they desire. Strain may result from a 
discrepancy between one's financial goal and the means to achieve that goal (Agnew, 1985). According to Agnew (1985), delinquency results when individuals are unable to achieve their goals through legitimate means. Agnew (1992) later expanded his Strain Theory to include sources of strain beyond finances to include families and schools (Agnew, 1992).

General Strain Theory (Agnew, 1992) not only recognizes strain as the result of financial stress, but also as a result of a lack of positive and encouraging relationships (Agnew, 1992). Adolescents may feel pressured into delinquency by anger stemming from negative relationships that do not support them in achieving their goals (Agnew, 1992). If youth are not encouraged, they may feel incapable of attaining their goals and consequently may resort to delinquency. If individuals are not treated in a manner that they want in their relationships, they may experience strain (Agnew, 1992). Youth who do not feel they are receiving guidance and nurturance from their relationships may react in anger and engage in delinquent behavior (Agnew, 1992).

Family and community members may even go further than not providing support to youth by actually preventing them from achieving positively valued goals, and removing or threatening to remove positively valued stimuli (Agnew, 1992). Teachers or parents who do not provide appropriate rewards for positive behavior, or who actually sabotage the youth's drive to succeed, can deter youth from pro-social activities and drive them towards deviant behaviors such as delinquency or substance abuse (Agnew, 1992; Loeber \& Stouthamer-Loeber, 1986). When youth are turned away from jobs or alienated from school and told that they will not succeed, they may turn to illegitimate means to reach financial goals. Youth who are repeatedly suspended and disciplined for 
negative behavior without receiving rewards for appropriate behaviors may feel that school success is an unreachable goal (Agnew, 1992; Eith, 2005; Gottfredson, 2001).

Strain can also result from the inability to escape painful situations (Agnew, 1992). Youth may turn to delinquency or substance abuse as a way to cope with abuse or other traumatic experiences. Youth who are at risk for delinquent behaviors often face many adverse factors in their environments including poverty, physical and sexual abuse, and negative school environments (Agnew, 1992; Farrington, 2005; Gottfredson, 2001). All of these factors can contribute to strain that the youth experiences and possibly result in delinquency (Agnew, 1992).

Agnew (1999) broadened his theory even further to include the effects of the community. He proposed that youth who came from deprived communities were more likely to experience strain (Agnew, 1999). These youth were more likely to experience anger and frustration and therefore were more at risk for engaging in delinquent activity (Agnew, 1999).

Youth who reside in aversive environments from which they cannot escape and those who are exposed to more stressful life events are more likely to be delinquent (Agnew, 1985, 1999). Furthermore, stressful life events seem to be more consequential in communities that are impoverished (Agnew, 1999). These youth may perceive fewer opportunities to escape the adversity and be more likely to react with anger and possibly engage in delinquent behavior (Agnew, 1999).

Agnew identified certain strains that are more likely related to crime (Agnew, 1997). These strains include parental rejection, child abuse and neglect, negative experiences in the school setting and criminal victimization (Agnew, 2001; Loeber \& 
Stouthamer-Loeber, 1986; Farrington, 2005). When youth experience this type of strain they are likely to experience disappointment, depression, fear and anger. Youth may blame their adversity on others causing them to become angry and create a desire to right the wrong, possibly even through delinquent means (Agnew, 1992).

\section{Risk Factors}

Risk factors are defined as the individual characteristics, interpersonal interactions or environmental conditions that increase the likelihood of poor developmental outcomes (Crosnoe, Erickson \& Dornbusch, 2002). Environmental pressures, such as disrupted families, antisocial parents, large family size, low family income, antisocial peers, schools with high delinquency rates, and high crime neighborhoods, which produce strain for youth, are considered to be risk factors for youth engaging in delinquent behavior (Farrington, 2005). While environmental factors such as exposure to poverty, residing in high crime neighborhoods and high unemployment rates have a direct impact on youth's functioning, the researcher will focus on individual characteristics which are consistent with the measures utilized in this study.

After reviewing the literature, Farrington (2005) found poor parental monitoring as the biggest predictor of delinquency among the child rearing factors. In addition, physically abused children were more likely to become violent. Children who witness parental violence and conflict are also more likely to engage in anti-social behavior (Farrington, 2005). Parental separation and single parent homes were predictors of conduct disorders (Farrington, 2005). The connection between family disruption and delinquency is thought to be due to an interference with attachment to the parental 
figures, the effect of multiple stressors such as parental conflict, parental loss, reduced economic resources and poor parental monitoring (Farrington, 2005).

Farrington's (2005) review of the literature provided evidence that other familial factors, such as parental involvement in criminal activity and large family size, increase the youth's involvement in delinquency. In addition to familial factors, youth who come from low SES backgrounds are more likely to engage in anti-social behavior (Farrington, 2005). Other mitigating factors, such as having delinquent peers, can be a strong predictor of delinquency (Farrington, 2005). Delinquent youth were also found to attend schools with high delinquency rates, were found to be mistrustful of teachers and students, had a low commitment to school, and attended a school with unclear and inconsistent rules (Farrington, 2005). Most offenders also came from inner-city neighborhoods that were deteriorated, disorganized, and had high mobility rates (Farrington, 2005).

Researchers (Lynskey, 1996; Smokowski, Mann, Reynolds, \& Fraser, 2004) have found risk factors to be cumulative. Smokowski et al. (2004) examined data collected during the Chicago Longitudinal Study which included 1,539 impoverished inner-city youth from birth to adulthood. The results demonstrated that cumulative family risk significantly increased the chances of juvenile court involvement and decreased the probability of completing high school (Smokowski et al., 2004). The more risk factors that youth are exposed to, the more likely they will exhibit externalizing behaviors. For example, Lynskey (1996) found that one or two family stressors seemed to make little difference, but several created high odds for serious behavior problems. 
Children with the highest levels of exposure to risk factors were found to be the least likely to exhibit adaptive behavior (Smokowski et al., 2004). Children who are at the highest risk for developing anti-social behaviors are those who experience the lowest level of protection due to being socialized in environments that are deficient of resources (Herrenkohl, Tajima, Whitney \& Huang, 2005). Herrenkohl et al. (2005) measured antisocial behavior in 176 children who had been abused. Their findings demonstrated that children who are raised in resource deficient environments are at highest risk for antisocial behavior.

Hanlon, Bateman, Simon, O’Grady and Carswell (2004) found that risk factors are not only cumulative; they are interactive with one another and are exponential. They used the Youth Questionnaire to assess self-reported substance abuse and delinquent acts in 375 inner-city youth who participated in a community diversion program. The results indicated that risk factors such as poverty seemed to increase the risk for other family risk factors such as parental substance abuse. In addition, poverty forces youth to live in communities that are plagued by crime making them more likely to become victims of crime.

Haynie, Petts, Maimon and Piquero (2009) described exposure to violence as "a serious public health concern that compromises adolescents by affecting their behavior and psychological wellbeing" (p. 269). Exposure to violence has been linked to increased risk for Post Traumatic Stress Disorder, school failure, depression and risky sexual behavior (Margolin \& Gordis, 2000). Violence exposure was found to be associated with distress symptoms in older and younger children (Reiss, 1993). More specifically, they found that being a victim of violence and witnessing violence were 
reliably related to greater levels of distress symptoms such as depression, anxiety, intrusive thoughts, and sleep problems (Reiss, 1993).

\section{Resiliency Factors}

Resiliency factors have been found to have a positive effect in reducing externalizing behaviors (Rogers, 2004). Resiliency factors are believed to protect a youth from delinquency by lessening the impact of risk factors (Rogers, 2004). Resiliency factors compensate for, or protect against, the effects of risks on healthy development (Ostaszeswski \& Zimmerman, 2006). The research divides resiliency factors into two models (Smokowski et al., 2004). First, the additive model describes resiliency factors as providing compensatory effects. According to this model, the presence of risk factors directly increases the likelihood of a negative outcome and the presence of resiliency factors directly increases the likelihood of a positive outcome. Risk and resiliency factors are seen as polar opposites (Smokowski et al., 2004). The second model is the interactive model in which resiliency factors only work in combination with risk factors and therefore have little effect when stressors are few (Smokowski et al., 2004). In this model, resiliency factors have little effect on development when stress is low; they only come into play when stress is high (Smokowski et al., 2004). This study focused on high school students in an urban setting who were considered to be at risk for conduct problems due to being exposed to a higher number of risk factors such as poverty and higher rates of exposure to violence. Thus, the additive model will guide the hypothesis in this investigation. Certain resiliency factors seem to make youth more resilient to the adverse conditions they are exposed to (Ostaszeswski \& Zimmerman, 2006). 
The construct of resiliency provides a framework for understanding why some children and adolescents who are exposed to high risk do not develop negative health and social outcomes (Ostaszewski \& Zimmerman, 2006). McKnight and Loper (2002) defined resiliency as the successful coping with or the overcoming of risk and adversity and the development of competence in the face of severe stress and hardship. They viewed resiliency as not eradicating risk but providing the individual with the ability to compensate for risk successfully (McKnight \& Loper, 2002). Harvey (2007) described resiliency as an active process wherein adolescents who have experienced trauma are able to utilize their strengths from one area to help them recover in other affected domains. Resilience is considered multidimensional in that youth who have been exposed to violence may be impaired in one or more areas of their lives (e.g., relationships) but demonstrate resiliency in other domains (e.g. academics, Harvey, 2007). Youth who feel strong connections to school or family are more likely to conform to conventional behaviors and are less likely to engage in acting out behavior (Herrenkohl et al., 2005). These social institutions are considered to be resiliency factors that can increase the resiliency of youth and reduce the risk of their participation in antisocial activity. Perkins and Jones (2004) also found social support as a resiliency factor among 16,313 adolescents who had been physically abused. In addition, religiosity, a positive view of the future, positive peer group, positive school climate, and involvement in extracurricular activities were all found to reduce risky and anti-social behavior in physically abused adolescents (Perkins \& Jones, 2004).

Smokowski, Mann, Reynolds, \& Fraser (2004) described three broad categories of resiliency variables. The first is individual attributes such as temperament, emotional 
reactivity, and sense of mastery. The second category includes family factors such as relationships with parental figures. The final category includes social supports outside of the family such as extended social supports (Smokowski et al., 2004). This study focused on the individual and familial domains since these factors have been found to moderate the effects of violence on youth (Luthar, 1991; Smokowski et al., 2004). Masten and Coatsworth (1998) provide a review of literature of resiliency factors in children. They divided the resiliency literature into three domains: attachment or relationships with caring adults, self-regulation or learning to control their emotions, behaviors, and attention, and a sense of competence including social competence, academic achievement and competence in the workplace (Masten \& Coatsworth, 1998). Both the Hemmingway Measure of Adolescent Connectedness (Karcher, 2005) and the Resiliency Scales of Children and Adolescents (Prince-Embury, 2005) are based on these constructs and will be utilized in this study.

There have been many studies exploring the relationship between risk and resiliency factors (Hart, O’Toole, Price-Sharps \& Shaffer, 2007; Harvey, 2007; McKnight \& Loper, 2002; Ostaszewski \& Zimmerman, 2006). However, few studies have explored the resiliency factors that moderate the risk factor of exposure to violence. Even fewer studies have explored the resiliency factors of youth who have been exposed to violence in a general population (Ozer, \& Weinstein, 2004). This study focused on the presence of specific resiliency factors in a general population to understand how they might keep at risk adolescents from manifesting conduct problems. Understanding which resiliency factors are related to decreased conduct problems provides information which could be utilized in the development of effective prevention and treatment programs 
which may prevent youth from engaging in delinquent behavior in the first place and deter youth from continuing to commit delinquent acts in the future.

Resiliency factors were stronger predictors of adolescent outcomes than risk factors (Smokowski et al., 2004). The more resiliency factors a youth is exposed to, the greater the protection from problem behaviors. Therefore resiliency factors can moderate the relationship between risk factors and problem behaviors (Jessor, Van Den Bos, Vanderryn, Costa \& Turbin, 1995). Resiliency factors have been shown to relate both directly and indirectly to adolescent involvement in problem behavior. The more resiliency factors adolescents experience the less likely they will be involved in aggressive or delinquent behavior (Herrenkohl et al., 2005).

Recent literature has focused on resiliency in youth who have been exposed to or become victims of violence (Hammack, Richards, Luo, Edlynn, \& Roy, 2004; Harvey, 2007; Perkins \& Jones, 2004;). One resiliency factor that was found to moderate the effects of exposure to violence was social support (Hammack et al., 2004). Hammack et al. (2004) examined 196 African American, sixth grade students who were exposed to violence or became victims of violence. Social support such as maternal closeness and spending time with family were found to reduce the incidences of anxiety and depression in youth who had been victims or witnesses of violence (Hammock et al., 2004).

Bell (2001) provided a list of ways to cultivate emotional resiliency in youth. He describes emotional resilience as a muscle that can be developed and strengthened. He offered strategies such as strengthening community partnerships, promoting physical health, improving bonding, attachment, and connectedness, improving self-esteem, increasing a sense of uniqueness and power, increasing social skills, problem solving 
skills, and helping parents to provide supervision and monitoring, and becoming more involved with their children were all found to reduce risky behavior in adolescents (Bell, 2001).

This study is based on the concepts of Strain Theory (Agnew, 1992) and assumes that exposure to violence is a source of strain for adolescents. According to Ganem (2010) "general strain theory argues that strain (i.e., stress) leads to negative emotion and that negative emotion leads to criminal behavior" (p. 167). It also utilizes the additive concept of resiliency and assumes that the more risk factors a youth is exposed to the more likely they will engage in externalizing behaviors and that resiliency factors can reduce the effect of these risk factors (Luthar, 1991; Masten, 1987). The purpose of this study was to examine the relationship between exposure to violence and resiliency (i.e., sense of mastery, relatedness to parents, teachers, and peers, and emotional reactivity), and externalizing behaviors in a sample of high school students. The definition of violence in this study was broad and included victimization through crime such as assaults with or without a weapon, robbery and sexual assaults, as well as indirect forms such as witnessing violence. This study draws on the work of Smokowski et al. (2004) which describes resiliency traits into three categories of self, family, and social supports and also on the work of Masten and Coatsworth (1998) who divide resiliency into three broad categories of relationships with others, self-regulation, and sense of competence.

It was hypothesized that rule breaking behavior and aggressive behavior would be positively related to the Direct Exposure to Violence Scale and negatively related to the Sense of Mastery Scale, the Sense of Relatedness Scale, the Emotional Reactivity Scale, 
the Connectedness to Friends Scale, the Connectedness to Parents Scale, and the Connectedness to Teachers Scale.

\section{Significance of the Study}

The potential implications for this study included prevention and intervention programs for at-risk youth to reduce the number of externalizing behaviors and therefore deter them from engaging in delinquent activity. Results from this study provided additional insight into how violence affects the development of youth and which resiliency factors can reduce those effects. A better understanding of the impact of violence on youth can lead to more effective delinquency prevention programs that focus on those resiliency factors that demonstrate a moderating effect on exposure to violence. The results of this study can also be utilized by school personnel to minimize the number of disruptive behaviors presented by students. Mental health professionals who work with youth who have been exposed to violence or who are exhibiting externalizing behaviors can also create treatment goals that enhance the development of resiliency factors in individuals and help them increase their sense of relatedness to others. 


\section{Chapter II}

\section{Review of the Literature}

Many researchers have studied the common characteristics of youth who exhibit externalizing behaviors and found several recurring themes including individual characteristics (e.g., low sense of mastery and high emotional reactivity) as well as environmental factors (e.g., exposure to violence, Fagan, Van Horn, Hawkins, \& Arthur, 2007; Gardner, Dishion, \& Connell, 2008; Hanlon et al., 2004). Youth who demonstrate poor academic achievement and learning disabilities were more likely to exhibit externalizing behaviors (Hart et al., 2007). Children and adolescents who are exposed to adverse environments such as poverty or exposure to violence are also more likely to have conduct problems (Hawkins, Herrenkohl, Farrington, Brewer, Catalano, Harachi, \& Cothern, 2000; Sullivan, Farrell, Kliewer, Vulin-Reynolds, \& Valois, 2007.

\section{Risk Factors}

For example, Ostaszewski and Zimmerman (2006) followed 850 high school aged youth through five years of high school to examine the relationship between risk and resiliency factors on adolescent poly-drug use. They found that the resiliency effects in poly-drug use were more predictive when youth were exposed to multiple risk factors (Ostaszewski \& Zimmerman, 2006). Hart, O’Toole, Price-Sharps, and Shaffer (2007) 
studied 124 adolescents to examine certain risk factors such as marital conflict, substance use, learning difficulties and school failure. The authors also looked at multiple resiliency factors including academic achievement, unfavorable attitudes towards violence, having a mentor, relationships with positive peers, and being involved in an extra-curricular activity. Non-delinquent youth were found to report low exposure to risk factors and high exposure to resiliency factors which moderate the impact of risk factors, while delinquent youth reported the opposite (Hart, O’Toole, Price-Sharps \& Shaffer, 2007). Other factors, such as being raised in poverty, have been found to contribute to a greater likelihood of involvement in crime and violence (Hawkins et al., 2000). Exposure to violence and exposure to drug dealing were identified as increasing the likelihood of youth engaging in externalizing behaviors (Rogers, 2004). These influences are all interrelated. Youth who live in poverty are more likely to live in neighborhoods with higher incidences of drug trafficking and higher rates of crime (Rogers, 2004).

Abuse, both physical and sexual, is another form of victimization that increases the likelihood that youth will engage in delinquent behavior. McShane \& Williams (2007) estimated that between 51 to 69 percent of delinquents had a history of abuse. Kelly, Thornberry, and Smith (1997) found that $45 \%$ of youth who had been abused eventually engage in delinquency later on. Travis (1996) found that almost half of the victims of childhood abuse and neglect had been arrested by their late twenties an early thirties. Of those who were arrested, 18 percent had been arrested for a violent crime. During adolescence, victims of abuse were at a higher risk than non-abused youth for a variety of behavior problems including delinquency and violence (Herrenkohl et al., 2005). Rogers (2004) expressed that childhood physical abuse and neglect resulted in a 
greater likelihood of later arrests for violent crime. Bright and Johnson-Reid (2008) asserted that poverty and maltreatment place youth at a higher risk of delinquency and that violent offending increased as a result of maltreatment. Kelley, Thornberry, and Smith (1997) also found that youth who experienced maltreatment during childhood were significantly more likely to display a variety of problem behaviors during adolescence including serious and violent delinquency, teen pregnancy, drug use, low academic achievement and mental health problems. Maltreated children were significantly more likely to become involved in a delinquency and engaged in delinquent activity more frequently (Kelley, Thornberry \& Smith, 1997).

Exposure to violence. A strong predictor of externalizing behaviors is youth who are exposed to violence (Sullivan et al., 2007). Youth who have been exposed to violence; both in the forms of crime and abuse are more likely to exhibit externalizing behaviors. A positive relationship between exposure to violence and community violence and aggressive behavior has been demonstrated through research (Moon, Blurton, \& Mccluskey, 2008; Sullivan et al., 2007). Continual exposure to violence was found to be predictive of serious delinquency among youth. McGee (2003) found that direct victimization was the best predictor of problem behaviors. Another study found that students with higher levels of victimization were more likely to engage in delinquency (Lowe, May, \& Elrod, 2008). Victimization was found to be 50 percent higher among violent juveniles than their peers who had not been victimized (Blum, Ireland, \& Blum, 2003). Roberts (2004) found that half of the males who were violent juvenile offenders were also violently victimized. Being the victim of violent or property crimes was found to be related to assault and theft offending in adolescence and adulthood (Daigle, Cullen 
\& Wright, 2007). Menard (2002) found that the same individuals who were victims of crime were also the perpetrators of crime. Furthermore, he found that the characteristics of victims of crime paralleled the characteristics of those who were arrested for crime. Violence victimization during adolescence was found to be a risk factor for most of the adult problem outcomes such as violent crime, further victimization, domestic violence both victimization and perpetration, violent and property crime perpetration and problem drug use (Menard, 2002).

Cooley-Quille et al. (1995) found that impaired social and behavioral functioning was significantly positively related to high exposure to community violence. High exposure to violence was inversely related to social competence in interpersonal functioning $(r=-.53, p=.03)$. Aggressive behavior was found to be positively associated with victimization by community violence and witnessing violence $(r=.14, p$ $<.05)$ for children who witnessed violence in grade $6,(r=.13, p<.05)$ for children who witnessed violence in grades 7 and $8,(r=.19, p<.01)$ for youth who were victims of violence, and $(r=.12, p<.05)$ for children who were victims of violence in grades 7 and 8. Anxious and depressive symptoms were also found to be positively associated with witnessing and victimization by community violence $(r=.13, p<.05)$ for children who witness violence in grade $6,(r=.16, p<.01)$ for children who were victims of violence in grade 6 , and $(r=.18, p<.01)$ for children who were victims of violence in grades 7 and 8 (Lambert, Ialongo, Boyd, \& Cooley, 2005).

Exposure to violence in the home or elsewhere increases a child's risk for involvement in violent behavior later in life (Hawkins et al., 2000). Children who witness violence in the home are more likely to become violent themselves (Hart et al., 
2007). Many boys who had been maltreated engaged in some later form of delinquency, aggression, fighting and serious physical violence (Herrenkohl et al., 2005). Witnessing violence and victimization is significantly associated with drug use and aggression (Sullivan et al., 2007). Being a victim of violence either committed during a crime or in the form of abuse both was found to increase their involvement in anti-social behavior.

\section{Resiliency Factors}

Not all youth who are exposed to violence turn to a life of crime. In fact most youth are able to thrive despite being exposed to numerous risk factors and are able to avoid delinquency (Wolkow \& Ferguson, 2001). Many children who experience adversity grow up to become well-adjusted, healthy adults (Wolkow \& Ferguson, 2001). Only a minority of youth who have been exposed to risk factors such as victimization develop severe and long lasting symptoms. Most youth who experience adversity recover with the help of a supportive environment (Harvey, 2007). Researchers (Luthar, 1991; McGee, 2002; Somkowski et al., 2004) became interested in understanding the difference between youth who succumb to risk factors and those who demonstrate a degree of resiliency. Smokowski et al.(2004) reviewed the data from the Chicago Longitudinal Study which surveyed 1,539 youth from 25 schools in central Chicago. Most of the youth came from impoverished neighborhoods and faced many risk factors. They found the resiliency factors were stronger predictors of adolescent outcomes than risk factors. The results of their analysis indicated that children who received early childhood interventions through the Child Parent Center preschool had lower rates of adolescent depression, fewer juvenile court petitions, and had a 36\% higher probability of completing high school or GED than other youth in the sample (Smokowski et al., 2004). 
Luthar (1991) examined 144 inner city ninth graders and found an internal locus of control where youth believe they can control what happens to them and the outcomes made them more resilient to aversive situations. Luthar (1991) also found that social competence served as a resiliency factor. Youth with strong ego development were also found to be more resilient to stress in their environment (Luthar, 1991).

Bullying behavior was found to be positively related to the emotional reactivity ( $r$ $=.49)$ and negatively related to a sense of mastery $(r=-.44)$ and to relationships with others $(r=-.40)$ (Thorne \& Kohut, 2007). The RSCA also demonstrated reasonable sensitivity in distinguishing clinical groups from each other (such as anxiety, depression, oppositional defiant disorder and ADHD) and from non-clinical groups (Thorne \& Kohut, 2007). Significant positive correlations were found between the Beck Youth Inventory-II scores and all of the RSCA scale and index scores for the normative sample (Prince-Embury, 2008).

McGee (2002) studied 500 African American high school students in Virginia to explore the impact of community violence on adolescent development. She found that males who were exposed to violence were more likely to exhibit externalizing behaviors such as engaging in delinquent acts and females were more likely to display internal symptoms and develop PTSD. She also found that being a victim of violence was the best predictor of problem behavior. Problem focused coping strategies were negatively related to externalizing problem behaviors including delinquency and emotion-focused coping strategies were positively related to externalizing problem behaviors. Problem focused strategies were positive ways of coping and emotion focused strategies were considered to be negative ways of coping (McGee, 2002). 
Herrenkohl et al (2005) found the level of exposure to positive developmental factors distinguished at-risk youth who became resilient from those who did not. They conducted a longitudinal study of 457 youth who were involved in the child welfare system due to physical abuse. They found that having a strong commitment to school, having parents and peers who do not endorse antisocial behavior, and participating in religious activities to be resiliency factors which decreased the youth's involvement in delinquent behavior or violence (Herrenkohl, et al., 2005). Increasing the number of resiliency factors resulted in lower risk for anti-social behaviors (Herrenkohl et al., 2005).

Resiliency or resiliency factors, just like risk factors, can be divided into several categories including individual characteristics, peer affiliation, family, school and community influences. Masten and Coatsworth (1998) reviewed the literature and divided the resiliency literature into three domains including competency, attachment, and self-regulation. Consistent with the findings of Masten and Coatsworth, this study groups resiliency factors into three constructs: sense of mastery, relatedness, and emotional reactivity.

Sense of mastery. Having a personal temperament that elicits positive responses from family members as well as strangers helps youth become more resilient (Rak \& Patterson, 1996). Youth who take an active approach toward problem solving and who tend to seek novel experiences tend to be more resilient (Rak \& Patterson, 1996). Adolescents who hold an optimistic view of their experiences even when exposed to adverse experiences and those who can maintain a positive vision of a meaningful life are also more likely to be resilient to risk factors (Rak \& Patterson, 1996). Positive social skills were strongly related to less delinquency (Fagan et al., 2007). Children with a high 
self-esteem and a positive social orientation are able to cope with adversity more effectively (Wolkow \& Ferguson, 2001). A review of the literature conducted by Arbona and Coleman (2008) found that good intellectual functioning, sociable, easygoing temperament and high levels of self-efficacy and self-esteem are all characteristics that contribute to adaptive resiliency in at-risk adolescents (Arbona \& Coleman, 2008).

Relatedness. Smokowski et al. (2004) found that a positive relationship with at least one parent or parental figure, family cohesion, warmth and harmony, supervision, and absence of neglect were all resiliency factors for youth. Adolescents who reported warm relationships with parents and came from well-organized households were buffered from the negative influence of deviant peers (Crosnoe, Erickson \& Dornbusch, 2002). A positive parent-child relationship and family support helped youth become more resilient to the effects of risk factors that lead to drug use and other risky behaviors by adolescents (Ostaszewski \& Zimmerman, 2006). Wolkow and Ferguson (2001) reviewed the literature and found that children who have a warm relationship with an adult tend to cope with hardship more effectively and had higher academic achievement, less substance abuse, less violent behavior, better relationships with parents and peers and better school attendance (Wolkow \& Ferguson, 2001). Attachment to parents was found to moderate the link between exposure to deviant friends and delinquency (Ferguson, Vitaro, Wanner, \& Brendgen, 2007). Youth who have a close bond with a caregiver the first year of life were found to be resilient children (Rak \& Patterson, 1996). Rak and Patterson's (1996) review of the literature found that a father's involvement also appeared to have a compensatory effect on adolescent problem behavior. They described several family factors that were associated with higher resiliency for youth. Families 
with four children or less who were spaced more than two years apart generally had more resilient children. Youth who received nurturing during their first year of life and who were infrequently separated from their primary caregiver were also more resilient. Families who had access to grandparents, siblings or neighbors who could help watch the children when the parents where gone kept children more resilient. Another resiliency factor in families was the existence of structure and rules in the house for adolescents (Rak \& Patterson, 1996). Adequate parenting that provides youth with warmth, support, limit setting and monitoring is associated with resiliency and adaptation during childhood development (Arbona \& Coleman, 2008).

Connectedness to school was also found to reduce externalizing behaviors in youth. The degree to which children are at risk for anti-social behavior during adolescence partly depends on the extent to which they invest in their schooling and become bonded to the institution of school (Hawkins et al., 2000; Herrenkohl et al., 2005). School connectedness and a commitment toward school education as well as academic competence were all found to increase youth resiliency (Ostaszewski \& Zimmerman, 2006). Youth attending a school with a positive school climate were found to be more resilient (Perkins \& Jones, 2004). Having opportunities for pro-social activities at school was negatively related to serious delinquency (Fagan et al., 2007). Adolescents who are connected to their school are less likely to use drugs and alcohol, engage in deviant behaviors, become pregnant and experience emotional stress (Perkins \& Jones, 2004). School commitment and importance predicted less violence, delinquency and status offenses (Herrenkohl et al., 2005). 
The presence of social support for youth enhances their ability to use problem solving techniques to resolve conflicts and therefore makes youth more resilient (Markston, Marshall \& Tyron, 2000). The availability of external resources, extended social supports, having a strong pro-social relationship with at least one caring adult all were shown to increase resiliency of youth to adversity such as poverty, being from a single parent home, and more than 4 children in the home, (Smokowski et al., 2004). Supportive relationships with an adult other than his or her parent helped youth become more resilient (Perkins \& Jones, 2004; Wolkow \& Ferguson, 2001). Juveniles who had someone they felt they could talk to when they needed help were less likely to be involved in substance abuse and delinquent behavior (Hart et al., 2007). Role models outside of the family such as teachers, school counselors, supervisors of after school programs, coaches, and mental health-workers, workers in community centers, clergy and good neighbors could help youth who were exposed to risk factors to become more resilient (Rak \& Patterson, 1996). Additional individuals who can provide support include older siblings, grandparents, aunts, uncles, and baby sitters (Wolkow \& Ferguson, 2001).

Victims of childhood adversity who identify at least one supportive adult from the past demonstrate higher academic achievement, less substance abuse, less violent behavior, better relationships with parents and peers, better school attendance, higher levels of self-understanding, better psychological adjustment, few conduct disorders, better coping skills, higher levels of self-understanding, a more positive self-image, heightened interpersonal skills, better adjustment and coping with ADHD and an overall improvement in psychological well-being (Wolkow \& Ferguson, 2001). Regardless of 
the nature or extent of the hardship to which a person is exposed, the presence of a warm and caring adult inevitably serves a resiliency function (Wolkow \& Ferguson).

In addition, youth who were involved in extra-curricular activities were more resilient (Perkins \& Jones, 2004). Youth who are involved in structured activities through church or school during after school hours have less of an opportunity to be involved in delinquent activity or influenced by delinquent peers (Hart et al., 2007). Religiosity was also found to be associated with less delinquency. Being involved in a religious community lowers the risk for anti-social behavior during adolescents (Herrenkohl et al., 2005). Perkins \& Jones explained that religion can provide adolescents with a sense of purpose and provides them with a sense of confidence that things will work out when they are facing adversity (Perkins \& Jones)

Emotional reactivity. Emotional reactivity describes the youth's ability to manage and adjust the occurrence, intensity, or duration of his or her feelings or emotions and his or her physiological response in a way that assists in the accomplishment of goals and positive outcomes (Spence, Young, Toon, \& Bond, 2009). Youth who can regulate their emotional reactivity were believed to react positively to stressful situations (Eisenberg, Gutrie, Babes et al., 1997).

Emotional dysregulation, on the other hand, is the youth's greater use of maladaptive coping strategies over more constructive coping strategies (Spence et al., 2009). Children with high negative emotional intensity and low inattentional regulation were found to be low in social competence (Eisenberg et al., 1995). Eisenberg and Fabes (1992) found that externalizing types of behavior such as aggression and anti-social acts were associated with low levels of behavioral and emotional regulation. Emotional 
dysregulation was also found to be associated with common mood disorder such as depressive disorder or bi-polar disorder (Demaree, Schmeichel, Robinson, \& Everhart, 2004). Emotional dysregulation is thought to increase the risk of future victimization (Spence et al., 2009). Ineffective coping responses such as aggressiveness may lead to more hostile interactions and increased risk for further victimization (Spence et al., 2009).

This paper examined the relationship between rule breaking behavior/aggressive behavior and direct exposure to violence. It was hypothesized that rule breaking behavior and aggressive behavior would be positively related to the Direct Exposure to Violence Scale and negatively related to the Sense of Mastery Scale, the Sense of Relatedness Scale, the Emotional Reactivity Scale, the Connectedness to Friends Scale, the Connectedness to Parents Scale, and the Connectedness to Teachers Scale. 


\section{Chapter III}

\section{Method}

This chapter focuses on the procedures of the current study including a description of the sample and definitions of the variables. The methods of data collection, including measures utilized, and data analysis will also be described.

\section{Participants}

The sample included 150 students of which $4 \%$ were in the $9^{\text {th }}, 71 \%$ were in the $10^{\text {th }}, 18 \%$ were in the $11^{\text {th, }}$ and $7 \%$ were in the $12^{\text {th }}$ grade in an urban high school in the Midwest. There was a $48 \%$ response rate from the 315 students asked to participate, 150 students returned the signed consent forms. Students ranged in age from 14 to 18 years old with a mean age of 15.9 years $(S D=0.90)$. The mean grade point average was 3.49 . The school was located in an inner ring suburb of a midsize city and included approximately 2,000 students. The sample was diverse and included 66\% European Americans, 12\% African Americans, 7\% Hispanic Americans, and 2\% Asian Americans. The sample included $52 \%$ of students with parents who were still married, $8 \%$ had parents who were separated, $27 \%$ had parents who were divorced, and $13 \%$ of their parents were never married. The majority of the students denied any arrests with only $11 \%$ of students reporting having been arrested. In addition $34 \%$ of the students reported 
being suspended or expelled from school. The majority of the students reported never being involved in a fight $(56 \%), 12 \%$ reported having been in one fight and $13 \%$ reported being involved in 2 fights. Only $4 \%$ of the students reported using a weapon during a fight and 14\% reported seriously hurting someone during a fight. Most students reported none or minimal use of drugs and alcohol with $49 \%$ of students reporting never using drugs or alcohol, $25 \%$ reported hardly ever using substances, $6 \%$ reported using 1-2 times per week, and only $20 \%$ reported using drugs or alcohol 3 or more times per week. Out of the 150 students who participated in the study, 138 completed all of the measures, however, only 121 participants were included in canonical correlation due to missing items.

\section{Hypotheses}

It was hypothesized that rule breaking behavior and aggressive behavior would be positively related to the Direct Exposure to Violence Scale and negatively related to the Sense of Mastery Scale, the Sense of Relatedness Scale, the Emotional Reactivity Scale, the Connectedness to Friends Scale, the Connectedness to Parents Scale, and the Connectedness to Teachers Scale.

\section{Measures}

Demographic Questionnaire. Demographic data were collected using a questionnaire designed for this study. Items included in the questionnaire were age, gender, grade level, current grade point average, race/ethnicity, parents' marital status, involvement in fights, school suspensions and expulsions, substance abuse and arrests for juvenile offenses. The readability of the demographic questionnaire was estimated to be at a $4^{\text {th }}$ grade reading level (Krantz, 2005). 
Children's Report of Exposure to Violence. The Children's Report of Exposure to Violence (CREV; Cooley, Turner, \& Beidel, 1995) is a self-report instrument that measures the lifetime exposure to violence either directly by being a victim or witness of violence or indirectly through the report of violence by others (i.e., Has your child ever been robbed or mugged?) or by media exposure through television or film exposure (i.e., How many times has your child seen somebody being robbed or mugged on T.V. or in the movies?) in children between the ages of 9 and 15 years. The types of violence assessed include being chased or threatened, beaten up, robbed or mugged, shot, stabbed or killed. The instrument includes 32 items, 29 of which are rated on a 5-point Likerttype scale with 1 = "no, never," 2 = "one time," 3 = "a few times," 4 = "many times," and 5 = "everyday" (Cooley-Quille, Turner, \& Beidel, 1995). The last three items are openended questions that are not scored and allow the respondent to include any other forms of violence that were not already assessed by the other items. These questions include "What other violent things have you seen on TV, video games, or movies?" and "What other violent things have you seen happening in real life to someone?" and "What other violent things have happened to you in real life?" These open ended questions were not included in the study due to the difficulty of quantifying such responses in a manner which would have allowed them to be incorporated into the canonical correlation.

The CREV is comprised of two scales, the Direct Exposure to Violence scale and the Indirect Exposure to Violence scale. The Direct Exposure to Violence scale includes twenty-four Likert-type items that assess how often the respondent has experienced violence against him or herself directly or witnessed violence to both strangers and familiar people. For example, "Have you ever been beaten up?" The Indirect Exposure 
to Violence scale included five items such as hearing about violence or being exposed to it through the media. An example item is "Have you ever been told that a stranger was chased or seriously threatened?" The scores from all twenty-nine items are totaled to obtain a Total Exposure to Violence Score. Only the Direct Exposure to Violence scale was utilized in this study due to the poor reliability of the Indirect Exposure to Violence scale.

The two-week test-retest reliability was .78 for Direct Exposure to Violence (Cooley-Quille et al., 1995). The Cronbach's alpha coefficient for Direct Exposure to Violence was .93 and the item factor total correlations for Direct Exposure to Violence ranged from .15 to .66. The correlation between the 29 Direct Exposure to Violence items and the Total score was .98 (Cooley-Quille et al., 1995). The alpha coefficient for the present sample was .95 .

The normative sample included 228 children who attended public elementary and middle schools in urban and rural communities. All of the children were in grades fourth through seventh and ranged in age between 9 to 15 years with the mean age being 11 . There were 116 females and 112 males; 74\% were African American, 19.7\% were Caucasian, $1.6 \%$ Hispanic, 1.3\% Native American, 1.3\% Asian, and 1.8\% were Bi-racial. The CREV demonstrated good construct validity. An exploratory factor analysis was conducted to determine the construct validity of the measure. The analysis indicated that $42.9 \%$ of the total variance was accounted for in a two factor model (Cooley-Quille et al., 1995). Twenty-four of the twenty-nine items loaded onto one of the two factors. The remaining five items loaded into additional factors that included one or two items. 
Twenty-one items loaded into the Direct Exposure to Violence scale and three items loaded into the Indirect Exposure to Violence scale.

One study found that lower levels of self-restraint predicted higher rates of witnessing violence and victimization, but neither witnessing violence nor victimization was related to changes in self-restraint over time (Sullivan, Farrell, Kliewer, Vulin, Reynolds, \& Valois, 2007). In addition, the researchers found that there were indirect effects of self-restraint on aggression and drug use through increased witnessing violence and victimization (Sullivan et al., 2007).

One study categorized 37 youth between the ages of 7 and 12 into low or high exposure to violence groups and administered the CREV. The researchers found that the high exposure group had a significantly higher CREV Total score than the low exposure to violence group $(r=19.36, \mathrm{p}<.001)($ Cooley, Turner, \& Beidel, 1995). Solberg, Carlstrom, Howard, and Jones (2007) utilized the CREV with 789 Latino and African American high school students in order to classify them into 6 clusters of varying academic risk. They found that the youth who scored higher on the CREV were at greater risk for academic failure than those who scored lower on the CREV. These findings lend support for the validity of the measure. The readability of the CREV is estimated to be at an $8^{\text {th }}$ grade reading level (Krantz, 2005).

The Resiliency Scales for Children and Adolescents. The Resiliency Scales of Children and Adolescents (RSCA; Prince-Embury, 2005) is a self-report inventory that measures the strengths and resiliency of youth between the ages of 9 and 18. The measure contains 64 items that are rated on a 5-point Likert-type scale with $1=$ "never," $2=$ "rarely," 3 = "sometimes," 4 = "often," and $5=$ "almost always." The 
standardization study included several different samples. The initial adolescent community sample included 200 youth and an additional clinical sample included 144 adolescents who were diagnosed with depression, anxiety, conduct disorder, and bipolar disorder. Data from two additional samples were collected that included 450 children from the community and 110 children with various mental health diagnoses. The RSCA is comprised of three scales: Sense of Mastery scale (MAS), Sense of Relatedness scale (REL), and Emotional Reactivity scale (REA). All three scales will be utilized in this study.

The Sense of Mastery (MAS) scale consists of twenty Likert-type items that measure optimism, self-efficacy and adaptability. More specifically, the scale measures optimism about life and one's own competence, self-efficacy associated with developing problem-solving attitudes, and adaptability demonstrated by receptivity to criticism and the ability to learn from one's mistakes (Prince-Embury, 2008). Sample items from this subscale include "If I try hard, it makes a difference" and "No matter what happens, things will be all right." Cronbach's alpha coefficient for the MAS scale was .85 . Testretest reliability for the RSCA was moderate to high. The interval between the first and second test ranged between 5 and 61 days with the mean being 12 days for the children's sample. The test-retest coefficient for the children's sample was .79 for MAS scale. The adolescent sample yielded a test-retest coefficient of .86 . The mean interval between testing for the adolescents was 8 days with a range of 3 to 23 days (Prince-Embury, 2008). The alpha coefficient for the MAS scale ranged from .83 to .94 demonstrating good internal consistency (Prince-Embury \& Courville, 2008). The alpha coefficient for the present sample was .92 . The RSCA successfully discriminated between clinical and 
non-clinical samples. A non-clinical group scored significantly higher on the MAS scale Prince-Embury, 2008). The Sense of Mastery scale score for children in the clinical sample was below average $(T=44)$ with and effect size of 1.0 ( Prince-Embury, 2007).

The Sense of Relatedness (REL) scale includes 24, 5-point Likert-type scale items that measure perceived access to support, sense of trust, comfort with others, and tolerance of differences. This scale assesses youths' comfort with others; trust in others, perceived access to support by others, and the capacity to tolerate differences with others. Sample items from this scale include "If something bad happens, I can ask my parents for help" and "There are people who love and care about me." The Cronbach's alpha coefficient for the REL scale is .89 . The test-retest reliability for the REL scale was .84 . The test-retest coefficient for the adolescent sample was .86 (Prince-Embury \& Courville, 2008). The alpha coefficient for the REL scale ranged from .89 to .95 (Prince-Embury \& Courville, 2008). The alpha coefficient for the present sample was .94. A non-clinical sample scored significantly higher on the REL scale (Prince-Embury, 2008). The Sense of Relatedness scale score for children in the clinical sample was below average $(\mathrm{T}=43)$ with and effect size of .96 (Prince-Embury, 2007).

The Emotional Reactivity (REA) scale has twenty Likert-type items that measure sensitivity, recovery, and impairment. The items assess the youths' sensitivity or the threshold for reaction and intensity of the reaction, length of time it takes to recover from emotional upset, and impairment while upset. This scale incorporates items such as "When I get upset, I stay upset for several days" and "When I am upset, I do things that I later feel bad about." Lower scores on the REA scale indicate resilience, while high scores indicate vulnerability. The Cronbach's alpha coefficient is .90 for the REA scale. 
The test-retest reliability for the children's sample was .88 and .88 for the adolescent sample for the REA scale. The alpha coefficient for the REA scale ranged from .90 to .95 for youth between the ages of 9-18 (Prince-Embury \& Courville, 2008). The alpha coefficient for the present sample was .92. The Emotional Reactivity Scale (REA) was found to be correlated with anxiety $(r=.65)$, disruptive behavior $(r=.67)$, depression $(r$ $=.74)$, and anger $(r=.76)$ (Prince-Embury, 2008). A clinical sample scored significantly higher on the REA scale (Prince-Embury, 2008). Child clinical disorder groups were pooled and matched with nonclinical children in a control group. The Emotional Reactivity score for children in the clinical sample was above average $(\mathrm{T}=59)$ with and effect size of -1.24 ( Prince-Embury, 2007).

A confirmatory factor analysis was performed by Prince-Embury and Courville, (2008) to determine the construct validity of the RSCA. The results of the analysis confirmed that a three-factor model was the best fit and supports the construct validity of the three scales. Another study found that there were no significant differences between males and females in the pattern of subscale loadings on all three factors (Prince-Embury, \& Courville). This indicates that the three-factor model fit for both males and females. This same study found partial factor invariance for different age groups. The loadings for the three core factors did not change significantly. The readability of the RSCA is estimated to be at a $6^{\text {th }}$ grade reading level (Krantz, 2005).

Hemmingway Measure of Adolescent Connectedness. The Hemmingway Measure of Adolescent Connectedness (Karcher, 2005) is a self-report instrument that measures the quality of a youth's relationships in three dimensions including self, others, and society for youth in grades six through twelve. The measure was developed using a 
series of exploratory and confirmatory factor analysis which revealed the same structure of adolescent connectedness across several samples (Karcher, Holcomb, \& Zambian, 2006). The adolescent version includes 57 items which require a five-point Likert type scale with $1=$ " not true at all," $2=$ "not really true," $3=$ "sort of true," $4=$ "true," $5=$ "very true" (Karcher, 2005).

The measure consists of 10 subscales which fall into three dimensions of connectivity. Connectedness to self includes two scales: Connectedness to Self in the Present and Connectedness to Self in the Future. These scales measure their experiences in current relationships and assess their awareness of their skills and talents which make them likeable by others. Connectedness to others includes 5 subscales: parents, friends, teachers, siblings, and peers. These scales measure the youth's involvement in and caring for their parents, how much time they spend with their friends, and their concern about their relationship with teachers. Connectedness to society includes school, neighborhood/community, and reading. These scales measure the importance that the youth places on school and the degree that they find their neighborhood to be comfortable and supportive (Karcher, 2003; Karcher \& Sass, 2010). This study will utilize the connectedness to others dimension to measure relatedness in youth including the Connectedness to Friends Scale, the Connectedness to Parents Scale, and the Connectedness to Teachers Scale.

The Connectedness to Friends Scale includes 6 items and assesses how much time the youth spend with their friends, how much they trust their friends, and how actively they communicate with friends about personal issues. Sample items include "I have friends I'm really close to and trust completely" and "I spend as much time as I can with 
my friends." The Cronbach's alpha coefficient for this scale is $r=.71$ (Karcher, 2003). The internal consistency estimates in a sample of 3,633 middle school aged youth was .78 (Karcher \& Sass, 2010). An additional study of 120 youth between grades eight to twelve yielded Cronbach's alpha coefficients of .67 and .73 (Karcher \& Lindwall, 2003). Karcher (2009) found post-test Alpha coefficients were .70. Karcher (2005) found inter item reliability with a Cronbach's alpha of .73. Analysis of a previous version using a rural sample of 209 adolescents in grades 9 to 11 in a Midwestern high school found a coefficient alpha of .66 for the Connectedness to Friends Scale (Karcher, 2001). A sample of 213 Caucasian $4^{\text {th }}$ through $6^{\text {th }}$ graders found a coefficient alpha of .72 (Karcher, 2003). The coefficient for the present sample was .76.

The Connectedness to Parents Scale contains 6 items that measure the amount of time youth spend with their parents and how well they get along with them. Items on this scale include "My family has fun together" and "My parents and I disagree about many things." The Cronbach's alpha coefficient for this scale is $r=.81$ (Karcher, 2003). Karcher and Sass (2010) found the internal consistency estimates of a sample of 3,633 middle school youth to be $\alpha=.80$. Another study of 120 high school students found reliability estimates to be $r=.71$ and .81 (Karcher \& Lindwall, 2003). Karcher (2005) found inter-item reliability Cronbach's Alpha to be .82) in 77 youth in grades four to eight. The Connectedness to Parents Scale in a previous version of the measure found a Coefficient alpha of .81 (Karcher, 2001). The coefficient alpha using the most recent version of this measure for a sample of $1454^{\text {th }}$ and $5^{\text {th }}$ graders is $\alpha=.71$ without the reverse scored item included in the analysis. The coefficient alpha for a sample of 213 
Caucasian $4^{\text {th }}$ to $6^{\text {th }}$ graders was $\alpha=0.74$ (Karcher, 2003). The coefficient alpha for the present sample was .83 .

The Connectedness to Teachers Scale contains five items which relate to the youth's relationship with his or her teachers. Sample items include "I care what my teachers think of me" and "I do not get along with some of my teachers." The Cronbach's alpha coefficient for this scale is $r=.84$ (Karcher, 2003). Internal consistency estimates in a sample of 3,633 middle school youth were .82 (Karcher \& Sass, 2010). The coefficient alpha for a previous version of this measure for the Connectedness to Teachers Scale was .73 (Karcher, 2001). The coefficient alpha for the most recent version of this measure in a diverse sample of $1454^{\text {th }}$ and $5^{\text {th }}$ grade youth is $\alpha$ $=.76$ without the reverse scored item. A similar coefficient alpha of .71 was found in a sample of 213 Caucasian, $4^{\text {th }}$ through $6^{\text {th }}$ graders (Karcher, 2003). The coefficient for the present sample was .78 .

The connectedness subscales have been found to correlate with self-esteem, resiliency, resiliency factors, social interest, and school attitude. Low scores of connection have been found to positively correlate with depression, violence, substance abuse and academic under achievement, risk factors, and social skills deficits (Karcher, 2003).

The measure has undergone considerable empirical scrutiny and has produced considerable validity evidence (Karcher, 2003). Previous studies using a prior version demonstrated a distinct factor structure, evidence of convergent and discriminate validity, and good one-month test-retest reliability (Karcher \& Sass, 2010). One sample of 3,633 youth displayed a good model fit, $\mathrm{X}(1439=12,555.58, \mathrm{p}<.0001, \mathrm{CFI}=965, \mathrm{RMSEA}=$ 
$.051, \mathrm{SRMR}=.048$. The model fit and modification indices which indicate minimal cross loadings, provide strong evidence of factorial validity. All the items had relatively large estimated standardized factor loadings on their corresponding factors (Karcher \& Sass, 2010). The readability of the Hemmingway is estimated to be at a $1^{\text {st }}$ grade reading level (Krantz, 2005.)

The Child Behavior Checklist-Youth Self-Report. The Child Behavior Checklist (Achenbach \& Rescorla, 2001) is a self-report inventory that measures emotional and behavioral problems in youth between the ages of 11 and 18 years old. The norming sample for the Syndrome Scales included 2,581 youth who were recruited from a national sample which included 40 United States, the District of Columbia, 1 Australian state, and England and an additional 13 outpatient and inpatient mental health services. There were 1,429 boys and 1,122 girls who participated in the study. Forty-seven percent were considered Non-Latino White, $23 \%$ were considered of African Descent, $17 \%$ were Latino, and $13 \%$ were considered mixed or other (Achenbach \& Rescorla, 2001). Certain items for the Syndrome Scales were matched according to the DSM-IV diagnostic categories to form the DSM-oriented Scales. These scales include the Affective Problems Scale which measures symptoms of Dysthymia and Major Depressive Disorder, the Anxiety Problems Scale which measures symptoms similar to Generalized Anxiety Disorder, Separation Anxiety Disorder, and Specific Phobias, Attention Deficit/Hyperactivity Problems Scale which measures symptoms related to ADHD, the Conduct Problems Scale which measures symptoms related to Conduct Disorder, the Oppositional Defiant Problems Scale which measures symptoms related to Oppositional 
Defiant Disorder, and the Somatic Problems Scale which measures items consistent with Somatization Disorder and Somatoform Disorder.

The first section of the measure, the Competence scales contain 7 questions that assess competence in three areas, activities participation, social competence and school performance.

The second half of the measure is the Problem Checklist that includes 112 items that make up 8 core Syndrome Scales including Anxious/Depressed, Withdrawn/Depressed, Somatic Complaints, Social Problems, Thought Problems, Attention Problems, Rule Breaking Behavior, and Aggressive Behavior. The Syndrome Scales can be grouped into the Internalizing scale that includes the Anxious/Depressed, the Withdrawn/Depressed, the Somatic Complaints, the Social Problems, Thought Problems, and Attention Problems scales and the Externalizing scale that includes the Rule Breaking Behavior Syndrome and Aggressive Behavior Syndrome Scales. The Internalizing and Externalizing Scales are then summed to provide a Total Problem Score. This study will utilize the two Syndrome Scales which make up the Externalizing Scale: the Rule Breaking Behavior Syndrome Scale and the Aggressive Behavior Syndrome Scale since they most closely matched the constructs of theoretical interest in this study.

The Rule Breaking Behavior Syndrome Scale measures a person's anti-social tendencies and includes 15 items measured on a three-point Likert-type scale and includes sample items such as "I break rules at home, school, or elsewhere" and "I run away from home." The Cronbach's alpha coefficient for this scale is .83 (Achenbach \& Rescorla, 2001). The alpha coefficient for the present sample was .86. The Aggressive Behavior Syndrome Scale measures the youth's display of verbal and physical 
aggression. It includes 17 items that are answered on a three-point scale and includes items such as "I get in many fights" and "I threaten to hurt people." The Cronbach's alpha coefficient for this scale is .88 (Achenbach \& Rescorla, 2001). The alpha coefficient for the present sample was .80. The YSR has proven to have good internal consistency. The test-retest reliability after 8 to 16 days is very high for most scales.

The content validity for the YSR items has been strongly supported by over 40 years of empirical research. All of the items on the YSR were scored significantly lower for referred than non-referred children ( $\mathrm{p}<0.01$ ) (Achenbach \& Rescorla, 2001; Achenbach \& Berube, 2001). There is a significant association between the YSR and the DSM diagnostic criteria (Kasius et al., 1997). The Rule Breaking Behavior Syndrome Scale and the Externalizing Scale were found to be correlated with the DSM checklist Conduct Disorders scores with correlation coefficients as follows, Rule breaking Behavior Syndrome Scale $(r=.63)$ and Externalizing Scale $(r=.62$, Achenbach \& Rescorla, 2001). The Aggressive Behavior Syndrome Scale was found to be correlated with the DSM checklist Oppositional Defiant Disorder scores with a correlation coefficient of $r=.64$ (Achenbach \& Rescorla, 2001).

Correlations were also found between the YSR and the BASC Parent Rating Scales, with the correlation coefficients ranging from $r=.38$ to $r=.89$. The correlation between the Rule Breaking Behavior Syndrome Scale and conduct problems was $r=.88$. The correlation between the Aggressive Behavior Syndrome Scale and aggression was $r=$ .61 to $r=.72$ and the correlation between Aggressive Behavior Syndrome Scale and the Conduct Problems Scales ranged between $r=.77$ and $r=.79$ (Achenbach \& Rescorla, 
2001). The readability of the YSR is estimated to be at a $4^{\text {th }}$ grade reading level (Krantz, 2005.)

\section{Procedures}

Permission was obtained from the high school principal to collect the data on site as well as permission from Cleveland State University's Institutional Review Board was obtained prior to beginning the study. Appendix A includes the letter granting permission from the Institutional Review Board to move forward in collecting data for the current study. A letter explaining the study along with a consent form for the parents and an assent form for the youth was sent home with all students in $9^{\text {th }}, 10^{\text {th }}, 11^{\text {th }}$ and $12^{\text {th }}$ grade enrolled in Stress Management and Health classes. The letters were distributed by the classroom teacher and students were asked to return the signed consent forms to the teacher. These letters are included in appendices B and C. The consent forms were collected by the teacher over a two-week period. The researcher acknowledges that there was a potential selection bias related to the characteristics of the students who returned the signed consent versus those that did not. Perhaps the students who returned the consent have a closer relationship with his or her parent or teacher which may potentially have skewed the results. There is little to do to minimize this bias however, it will be discussed further in the discussion section. All students who returned the consent form completed the measures during class time. The students were administered the Youth Self Report, The Resiliency Scales for Children and Adolescents, the Children's Report of Exposure to Violence, the Hemmingway Measure of Adolescent Connectedness and a demographic questionnaire. The measures were counterbalanced in order to avoid order effect. 
Students' names were checked at the door to ensure that a consent form was returned. Students were then given the instructions for completing the measures and were asked to complete them individually without consulting with their peers. Students were again reminded that their participation in the study was completely voluntary and that they could choose to withdraw from the study at any point.

The measures were then distributed and students were asked to complete the measures. Each packet of measures was assigned a number to ensure that the same measures from an individual were grouped together. No identifying information was attached to the measures to ensure anonymity.

\section{Data Analysis}

A canonical correlation was used to analyze the data. This type of correlation allows for exploration of multivariate effects simultaneously (Thompson, 2000). This method provides a way to study the relationship between the independent variables (exposure to violence, sense of mastery, sense of relatedness, emotional reactivity, and relatedness to parents, teachers, and peers) and the dependent variables (delinquent behavior and aggressive behavior). Using a multivariate method of analysis decreases the likelihood of experimentwise (Type I) errors which can occur when running several univariate tests with a single sample. In addition, a canonical correlation allows the experimenter to examine how each variable affects the relationship by producing an effect size for those variables (Thompson, 2000). 


\section{CHAPTER IV}

\section{Results}

\section{Preliminary Analysis}

The results of the preliminary analysis including the means and standard

deviations for each of the predictor and criterion variables as well as the correlation coefficients and reliability coefficients for all of the scales are summarized in Table 1.

The reliability coefficients for the present sample were high for all of the scales and ranged from .76 to .95 and are reported in Table 1 on the diagonal. 
Table 1

Means, Standard Deviations, Pearson Product-Moment Correlation Coefficients, and

Reliability Coefficients of Rule Breaking Behavior, Aggressive Behavior, Exposure to

Violence, Resiliency, and Connectedness Subscales $(N=150)$.

\begin{tabular}{|c|c|c|c|c|c|c|c|c|c|c|c|}
\hline Scale & $\mathbf{M}$ & SD & 1 & 2 & 3 & 4 & 5 & 6 & 7 & 8 & 9 \\
\hline \multicolumn{12}{|l|}{ Criterion Measures } \\
\hline $\begin{array}{l}\text { 1. Rule Breaking Behavior } \\
(n=145)\end{array}$ & 7.3 & 5.3 & .86 & & & & & & & & \\
\hline $\begin{array}{l}\text { 2. Aggressive Behavior } \\
(n=143)\end{array}$ & 8.8 & 6.2 & $.74^{* *}$ & .80 & & & & & & & \\
\hline \multicolumn{12}{|l|}{ Predictor Measures } \\
\hline $\begin{array}{l}\text { 3. Exposure to Violence } \\
(n=150)\end{array}$ & 36.6 & 24.9 & $.40^{* *}$ & $.39 * *$ & .95 & & & & & & \\
\hline 4. Sense of Mastery ( $n=144)$ & 55.5 & 12.6 & $-.38 * *$ & $-.43 * *$ & $-.22 * *$ & .92 & & & & & \\
\hline 5. Relatedness $(n=138)$ & 68.2 & 15.3 & $-.18^{*}$ & $-.28 * *$ & -.12 & $.75 * *$ & .94 & & & & \\
\hline $\begin{array}{l}\text { 6. Emotional Reactivity } \\
(n=139)\end{array}$ & 28.6 & 13.8 & $.54^{* *}$ & $.67^{* *}$ & $.38^{* *}$ & $-.49 * *$ & $-.36 * *$ & .92 & & & \\
\hline $\begin{array}{l}\text { 7. Connectedness to Friends } \\
(n=150)\end{array}$ & 23.4 & 4.5 & .14 & .39 & -.03 & $.23^{* *}$ & $.51^{* *}$ & .05 & .76 & & \\
\hline $\begin{array}{l}\text { 8. Connectedness to Parents } \\
(n=150)\end{array}$ & 18.2 & 4.5 & $-.46 * *$ & $-.39 * *$ & $-.23 * *$ & $.58^{* *}$ & $.46^{* *}$ & $-.40 * *$ & .15 & .83 & \\
\hline $\begin{array}{l}\text { 9. Connectedness to Teachers } \\
(n=150)\end{array}$ & 21.9 & 5.1 & $-.44 * *$ & $-.36 * *$ & $-.17^{*}$ & $.53^{* *}$ & $.38^{* *}$ & $-.27 * *$ & .13 & $.57^{* *}$ & .78 \\
\hline
\end{tabular}

Note. $M=$ mean, $S D=$ standard deviation, ${ }^{*} p<.05$. ${ }^{* *} p<.01$, Coefficient $\alpha$ is on the diagonal.

\section{Multivariate Analysis}

A canonical correlation was used to determine the relationship between the predictor and criterion measures. One side of the model included rule breaking behaviors and aggressive behaviors reported by youth. The other side of the model incorporated the predictor measures and included exposure to violence, sense of mastery, relatedness, emotional reactivity, connectedness to friends, parents, and teachers. The full canonical model was significant and accounted for $37 \%$ of the variance between canonical composites, Pillai's $V=.73, F(14,226)=9.38, p<.001$. To assess the precise nature of the relationship between the predictor and criterion variables, a dimension reduction 
analysis was performed. Two significant canonical roots emerged from the model. The structure coefficients representing the correlations between the criterion and predictor variables and canonical variables, as well as the associated weights are presented in Table 2. The first canonical root accounted for $79 \%$ of the overall variance $\left(R_{c}^{2}=51\right)$ between canonical composites, and therefore accounted for $40 \%$ of the non-redundant aggregate variance of the full model (Wilk's Lambda $=.38, F(14,224)=110.00, p<.001)$. This root was characterized by heavy positive loadings of emotional reactivity and heavy negative loadings of Connectedness to Parents and Connectedness to Teachers and a moderate positive load of Sense of Mastery. The other side of the model was characterized by heavy positive loadings of Aggressive Behavior and Rule Breaking Behavior. Structure coefficients greater than .60 were considered to be a heavy loading, coefficients ranging from .40 to .60 were considered to be a moderate loading, and coefficients below .40 were considered a low loading. Loadings of less than .30 are not usually interpreted (Tabachnick \& Fidell, 2001). These loadings suggest that youth who have high exposure to violence and a high level of emotional reactivity and a low connection to parents and teachers are more likely to engage in aggressive behavior and rule breaking behavior.

The second canonical root accounted for $21 \%$ of the overall variance $\left(R_{c}{ }^{2}=22\right)$ between canonical composites, and therefore accounted for $5 \%$ of the non-redundant aggregate variance of the full model (Wilk's Lambda $=.78, F(6,113)=5.34, p<.001)$. This root, which accounted for only a very small amount of the variance, was characterized by a moderate positive loading of Relatedness and a moderate negative 
loading of Emotional Reactivity. The other side of the model was characterized by a low loading of Rule Breaking Behavior and Aggressive Behavior.

Table 2

Structure Coefficients for Significant Canonical Roots $(n=121)$

\begin{tabular}{llc}
\hline Variables & \multicolumn{2}{c}{ Structure Coefficients } \\
\cline { 2 - 3 } & Root 1 & Root 2 \\
Predictor Set & & \\
$\quad$ Exposure to Violence & .58 & .02 \\
Sense of Mastery & -.56 & .15 \\
Relatedness & -.36 & .50 \\
Emotional Reactivity & .84 & -.43 \\
Connectedness to Friends & .12 & .35 \\
Connectedness to Parents & -.61 & -.28 \\
$\quad$ Connectedness to Teachers & -.60 & -.34 \\
Criterion Variables & & .34 \\
Rule Breaking Behavior & .94 & -.36 \\
Aggressive Behavior & .93 & \\
\hline
\end{tabular}




\section{Chapter V}

\section{Discussion}

\section{Overview}

The current study attempted to understand the relationship between exposure to violence, sense of mastery, connections with parents, teachers and friends, and emotional regulation, and conduct behaviors and aggressive behaviors in youth. The findings confirmed the hypothesis that rule breaking behavior and aggressive behavior would be positively related to direct exposure to violence and negatively related to a sense of mastery, relationships, emotional reactivity, and connectedness to parents, friends and teachers. The canonical correlation found that those youth who had a high exposure to violence and also high emotional reactivity and expressed a poor connection with parents and teachers also engaged in aggressive and rule breaking behaviors. Youth who do not have a positive relationship with their parents or a strong connection to teachers are less likely to develop a high sense of mastery. In addition, youth who are exposed to violence are more likely to struggle with regulating their affect and may display more explosive behaviors which can alienate them from family and teachers.

Relatedness to others as measured by the RSCA and connectedness to friends was not found to be significantly related to rule breaking and aggressive behavior. 
Therefore, it appears as though youth who have strong relationship with parents and teachers are related to youth who exhibit conduct problems. However, relationships with peers do not seem to be related to rule breaking and aggressive behavior indicating that relationships with peers are less of a protective factor. The second canonical root found a moderate relationship between relatedness and low emotional reactivity, and aggressive behavior. Youth who reported positive relationships with others on the RSCA and low emotional reactivity reported less aggressive behavior. These relationships were found to be significant despite the restricted range of exposure to violence in this sample of youth. The CREV-R has a range of 0-244, however, youth in the present sample had a more limited range between 0 and 192 with a mean score of 37 . These findings have been demonstrated in previous studies involving clinical populations (Farrington, 2005; Hanolin, et al., 2004; Hart, O’Toole, Price-Sharps \& Shaffer, 2007). However, this study generalizes similar findings to include youth in a general population. Therefore children who are at risk for conduct problems and aggressive behavior can be identified early in an effort to prevent the behaviors from manifesting in the first place.

The current study contributed to the literature by expanding our understanding of resiliency in typical high school students who would not be considered to have clinical levels of distress. The students in the current sample did not report a great deal of exposure to violence and reported above average grade point averages. Even in youth who reported low exposure to violence, those who reported low connections to teachers and parents reported engaging more in rule breaking and aggressive behavior and lower sense of mastery. In addition, youth who reported high emotional reactivity also reported more rule breaking behavior and aggressive behavior. Therefore, parents and teachers 
might be encouraged to play a role in decreasing aggressive and rule breaking behavior in youth simply by developing a more nurturing relationship with those youth. Helping all children develop a higher sense of mastery and increasing their ability to regulate their affect will also reduce the number of aggressive and rule breaking behaviors, regardless of exposure to violence. By utilizing a general population, rather than a clinical population, this study demonstrates the need for preventative programs in schools and stresses the importance of counselors including family systems work in helping increase resiliency in youth.

\section{Summary}

Previous literature has demonstrated that youth who have been exposed to violence were more likely to engage in delinquent and aggressive behavior (Lowe, May, \& Elrod, 2008; McGee, 2003; Moon, Blurton, \& Mccluskey, 2008; Sullivan et al., 2007). This study expanded the previous research by exploring the relationship between resiliency factors such as sense of mastery, connection to parents, teachers, and friends, and emotional regulation in youth who have been exposed to violence using a general population. The result showed that youth who reported less connection to their parents and teachers, a low sense of mastery, and a high emotional reactivity, also reported more delinquent and aggressive behaviors. These findings expanded previous literature by extending it to a general population of youth who scored low in their exposure to violence. This means that youth who demonstrate these risk factors might be followed more closely to assess their potential to engage in aggressive and rule breaking behavior. Once these youth have been identified they might benefit from prevention programs to help them increase their resiliency and avoid further difficulties. 
The findings in this study are consistent with previous studies (Farrington, 2005; Hart, O’Toole, Price-Sharps \& Shaffer, 2007). Farrington (2005) conducted a review of the literature and found that a poor attachment to parents resulting from parental conflict, parental loss, reduced economic resources, and poor parental monitoring were all predictors to delinquent behavior. Rogers (2004) identified exposure to violence and exposure to drug dealing to increase the likelihood of youth engaging in externalizing behaviors. This was consistent with the findings of the current study that youth who reported a poor connection with their parents reported more rule breaking and aggressive behavior. Farrington (2005) also found delinquent youth were more likely to be distrustful of their teachers and had a low commitment to school. The current study found that youth who had higher self-reports of rule-breaking behavior and aggressive behavior also reported a lower sense of connectedness to teachers. Herrenkohl et al., (2005) found similar findings that youth who feel strong connections to school or family were more likely to conform to conventional behaviors and less likely to engage in acting out behaviors.

Resiliency factors were found to be related to youths' involvement in aggressive or delinquent behavior (Herrenkohl et al., 2005). Hammack et al. (2004) found that social support such as maternal closeness and spending time with family were found to moderate the effects of exposure to violence in 196 African American sixth grade students. Bell (2001) found that improving bonding, attachment, connectedness, improving self-esteem, increasing a sense of uniqueness and power, and helping parents to provide supervision and monitoring and becoming more involved with their children were all found to reduce risky behavior in adolescents. A study by Smokowski et al. 
(2004) found similar results in that a positive relationship with at least one parent or parental figure, family cohesion, warmth and harmony, supervision, and absence of neglect were all resiliency factors for youth.

Exposure to violence was found to be related to more rule breaking behavior and aggressive behavior. This is consistent with studies such as Sullivan et al., 2007 who found exposure to violence to be a strong predictor of externalizing behaviors. Moon, Blurton, and Mccluskey, (2008) also found a positive relationship between exposure to violence and community violence and aggressive behavior. McGee (2003) found direct victimization was the best predictor of problem behaviors. Lowe, May, and Elrod (2008) found that students with higher levels of victimization were more likely to engage in delinquency. A study conducted by Roberts (2004) found that $50 \%$ of the males who were violent juvenile offenders were also violently victimized. Menard (2002) found similar findings that the same individuals who were victims of crime were also perpetrators of crime. Eisenberg and Fabes (1992) found that that low levels of behavioral and emotional regulation were found to be associated with externalizing behaviors such as aggression and anti-social acts.

This study found a high sense of mastery was negatively related to aggressive behavior and rule breaking behavior. Youth who reported low emotional reactivity also reported less aggressive behaviors and conduct problems. Previous studies demonstrated similar findings. For example, Luthar (1991) also found that youth with a strong ego development were found to be more resilient to stress in their environment. Thorne and Kohut (2007) found that bullying behaviors were negatively related to a sense of mastery and also to relationships with others but positively related to emotional reactivity. 
Children with a high self-esteem and a positive social orientation were found to be able to cope with adversity more effectively (Ferguson \& Wolkow, 2001). Arbona and Coleman (2008) reviewed the literature and found that good intellectual functioning, sociable, easy temperament, and high levels of self-efficacy and self-esteem were adaptive factors in increasing resiliency in at-risk adolescents.

\section{Limitations}

The data for the current study was collected using self-report measures which always leave room for error due to over- or under-reporting of symptoms. While the sample was random and all students enrolled in health and stress management were invited to participate there may be some bias due to the nature of parents who provided consent for their children to participate in the study. Parents who consented may have overall had better relationships with their children resulting in a skewed sample. Additional bias may have resulted from the youth who chose to participate in the study. Youth who experienced a high rate of exposure to violence may have shied away from participating in the study not wishing to report their experiences. In addition, the stress management and health classes sampled for this study may have included youth with higher grade point averages. Youth who obtained higher GPA's may have been more likely to join in the study than those who earned lower grades. Although no identifying information was connected to the data, students may still have held reservations about self-reporting exposure to violence or behavioral concerns in a school setting. Students were reminded that their participation was completely voluntary and that they could stop at any point in the study. In addition, during the collection of the data there was an unfortunate incident of a school shooting which occurred in a nearby school. During the 
second phase of data collection students were informed of a potential threat which proved to be a false alarm. While the incident may have increased interest in the topic of exposure to violence and may have resulted in more students willing to participate in the study they may have been less willing to disclose any aggressive behaviors in fear of receiving consequences for disclosures. Another limitation was that the present study was a correlational study which used cross-sectional data and therefore causal conclusions could not be drawn. Longitudinal research would provide further information allowing for causal conclusions.

\section{Implications for Theory}

According to Agnew (1985) being exposed to adverse conditions increases the likelihood that a juvenile will experience strain and therefore engage in delinquent behavior. Strain can result from financial stress, lack of positive and encouraging relationships both within their families and schools (Agnew, 1992). General strain theory posits that if youth do not feel as if they have nurturing relationships they may react in anger and engage in delinquent behavior (Agnew, 1992). Youth can be pushed towards engaging in externalizing behaviors such as delinquency or substance abuse rather than engaging in pro-social activities by teachers or parents who do not reward positive behavior (Agnew, 1992). The findings from the current study are consistent with Agnew's (1985) General Strain Theory. Youth who were exposed to violence and experienced less connections with parents and teachers reported engaging in more rule breaking behaviors and aggressive behaviors. Regardless of exposure to violence, it may be that youth who experience strain may be swayed from engaging in externalizing behaviors by fostering nurturing relationships and increasing a sense of mastery. This 
raises questions as to whether youth engage in delinquent behavior due to experiencing strain or due to a deficiency in resiliencies such as a low sense of mastery and poor relationships with parents and teachers. Further research could be conducted to explore the relationships between sources of strain and relationships and sense of mastery to better determine if increasing the resiliency in youth can moderate the effects of other risk factors and therefore decrease the likelihood of youth engaging in externalizing behaviors. Research to determine which sources of strain appear to be more related to conduct problems would help school personnel and teachers identify those youth most at risk and in need of more intensive interventions. Exposure to violence may lead to youth experiencing symptoms of Post- Traumatic Stress Disorder (PTSD) including a sense of foreshortened future, hyper-viligilance, and increased startle response, which can be additional sources of strain for youth. Further research could focus on youth who have been diagnosed with PTSD to determine which resilience factors reduce the rates of rule breaking behavior and aggressive behavior in youth who have been diagnosed with PTSD.

\section{Implications for Practice}

Previous research found that treating chronic delinquency and deviant behavior has demonstrated to be ineffective (Kazdin, 1987). Therefore prevention may be more effective in reducing juvenile delinquency rates (Yoshikawa, 1994). By utilizing the findings in this study counselors and teachers can identify youth who are at risk to engage in externalizing behaviors by assessing their connections to parents and teachers. Youth who are experiencing disruptions in the home due to divorce, parental incarceration, parental substance abuse, or death of a parent could be provided with extra interventions 
to help promote healthy relationships with other caregivers. Students who truant themselves from school or do not appear to have developed nurturing relationships with teachers in the school should be placed in activities which allow more interactions with teachers to help promote a stronger bond. Rather than suspending youth or placing them in detention for truancy or behavioral difficulties youth should be encouraged to work more closely with teachers and counselors to identify the underlying causes of their behaviors and interventions could target those causes. Programs such as school based truancy officers, home school liaisons, and homework groups might help youth feel more connected to their school and teachers rather than further alienated.

Prevention efforts could focus on increasing a sense of mastery and emotional regulation. Including activities which strengthen self-mastery into the curriculum would help youth become more resilient (Leiss, Pekrun, Blum, Muller, Messner, 2012). Teachers and counselors could teach weekly lessons on increasing self-esteem, improving coping strategies, dealing with bullying behaviors, reducing stress, and improving anger management (Beat the bullies, 2012). Helping youth identify their strengths and fostering classrooms which allow for youth to express their strengths would also help to increase youths' sense of mastery. Cooperative learning experiences which allow youth to work as part of a group can allow youth to feel more connected to peers and to their school (Ebrahim, 2012). Using multi-modal teaching strategies which allows youth to demonstrate their strengths through creative projects can help promote a more positive sense of mastery. Youth who struggle with verbal skills can be provided with the opportunity to express themselves through visual means such as posters, models, or power point projects. Providing a variety of extra-curricular activities for youth could 
provide additional opportunities for youth to increase their sense of mastery and increase their self-esteem. Youth can increase their sense of connectedness to schools and teachers by participating in sports, music programs, or student organizations facilitated by teachers. Book clubs and discussion groups can also be utilized to help marginalized students feel more connected to the school as well as the teachers. Increasing emotional regulation can be incorporated into the curriculum including anger management, stress management, and problem solving. Youth identified as being at higher risk due to experiencing adverse experiences such as exposure to violence or experiences which interfere with parental bonding such as divorce, parental incarceration or parental substance abuse could be referred for additional intervention efforts such as individual and group counseling facilitated by the guidance counselor. Students needing more intensive therapy could be referred for additional services at a counseling center. Contracting school based therapists can provide another means for at risk youth to access services that may not be able to receive services otherwise.

Schools could also work to increase all students' connection to school. Assigning students to a team of teachers can help students feel more connected to those teachers and could also aid in the identification of students who are at risk. Team teaching provides teachers with the ability to meet on a regular basis with school counselors to discuss concerns about particular students in an effort to identify those needing additional services. Teachers who have formed a bond with a particular youth can also provide insight into effective intervention efforts as well as become a resource for that student during difficult times. Perhaps the student can use that teacher's classroom as a safe place to work on affect regulation when they are experiencing difficulties in other 
classrooms. Teachers can get to know their students through journals or simply greeting students as they enter the classroom each day helping students recognize that teachers are interested in their feelings. Increasing the parent school link can also increase a student's connection to school. Having parent night to allow parents time to meet their son or daughter's teachers several times throughout the year can increase communication and also help identify problems earlier. Teachers can also increase communication through phone calls, emails, and letters home. Communication needs to include positive efforts by students rather than just focusing on negative behaviors. A sense of community can also be fostered through monthly family activities such as movie night, science fairs, and pot luck dinners. Extra-curricular activities such as gardening club or walking club can also encourage parental participation to encourage a parent-school link as well as encourage a stronger parent-child bond.

Leaders within the school could also form partnerships with community and business leaders. Principals and counselors can invite members from community businesses and organizations to volunteer within the schools. Employees and CEO's can speak with youth about careers. Businesses can sponsor schools and serve as mentors for the youth as well as volunteer to coach sports teams, teach art and music or simply donate money to sustain these types of extra-curricular activities. Businesses can also be recruited to offer internships and volunteer opportunities for students so they can gain experience to help them obtain employment in the future.

Counselors can help increase resiliency in youth by utilizing a family systems approach to identify and treat barriers which interfere with the child-parent bond whenever appropriate (Welsh, 1999). Regular parent workshops which teach nurturing 
parenting strategies, effective communication techniques, and how to set limits with children would promote healthier parent-child relationships. Parents who have been identified as abusive or inappropriate should be referred to the department of children and family services in order to maintain the safety of the child and avoid inadvertently causing more abuse towards the child. Therapists could also work with the parents to increase monitoring of their children and provide clear expectations and consistent consequences during these workshops. When parents are not available or are not appropriate, adult caregivers or mentors can be identified to serve as surrogate caregivers or mentors for the youth. Therapy could also focus on increasing a sense of mastery. Youth can be encouraged to identify and verbalize their strengths. Negative selfstatements which decrease their sense of mastery could be challenged and replaced using cognitive-behavioral techniques. Emotional regulation could also be the focus of treatment. Mindfulness based techniques which teach accepting life experiences without judging or assigning emotional reactions to those events can help increase affect regulation in youth (Coholic, 2011). Counselors can teach mindfulness techniques in the classrooms and teachers can be taught to reinforce a less judgmental way of reacting in their classroom. In addition teaching relaxation techniques and problem solving strategies can also be taught by teachers and counselors in the classroom to help youth become more resilient in stressful situations. Elementary school teachers can take several breaks throughout the day to help students practice relaxation techniques and light exercise to help promote better emotional regulation. Middle schools and high schools can also offer stress management as part of the curriculum in health and physical education. Regular school assemblies which teach self-care through exercise and good 
nutrition can also increase a youth's ability to modulate their emotional reaction and help promote healthier lifestyle choices.

\section{Implications for research}

This study focused on the relationship between exposure to violence, resiliency traits, and aggressive and rule breaking behaviors. Future research could focus on exploring additional risk factors such as poverty, parental incarceration, or divorce. Additional resiliency factors could also be explored such as a relationship with grandparents or extended family, playing sports, maintaining part time employment, and relationship with siblings. Research could also explore what factors improve healthy relationships between youth and their parents and what school and community factors increase the connection youth have with their school. Additional correlational studies could provide more insight into the relationship between other sources of strain for youth to help identify youth at most risk for behavioral difficulties and aggressive behaviors. Additional correlational studies would provide more insight into which resiliency factors were negatively related to aggressive behavior and conduct problems. Future researchers could also explore the relationship between risk factors and internalizing behaviors such as anxiety, depression, or low self-esteem. Research which identifies additional traits which interfere with interpersonal skills would be beneficial to help identify barriers to positive parental and teacher relationships in order to help teachers and counselors to address those barriers.

Longitudinal studies which explore the relationships between risk and resiliency would provide more insight into causal factors of externalizing behaviors and would 
provide crucial information for developing more effective prevention and intervention efforts.

Increasing resiliency in all youth by increasing the parental bond, his or her connection to school, and helping them develop a healthy self-concept are some ways that counselors and teachers can decrease the likelihood that youth will engage in aggressive or rule breaking behaviors. These prevention efforts can be incorporated into the school curriculum and reinforced at home by parents. Youth who are more at risk such as those exposed to violence or due to disruptions in the family unit could be identified early and referred for counseling services to minimize the impact of traumatic experiences or family disruptions and help youth to effectively cope and avoid emotional and behavioral difficulties. Since intervention efforts do not appear to be as effective in reducing delinquency, a more effective approach is to increase resiliency in all youth and provide early preventative measures to youth at risk prior to the onset of any behavioral difficulties. 


\section{References}

Achenbach, T. M., \& Rescorla, L. A. (2001). Manual for ASEBA School-Age Forms \& Profiles. Burlington, VT: University of Vermont, Research Center for Children, Youth, \& Families.

Agnew, R. (1985). A revised strain theory of delinquency. Social forces. 64(1), 151167. doi: $10.2307 / 2578977$

Agnew, R. (1992). Foundation for a general strain theory of crime and delinquency. Criminology, 30 (1), 47-87. doi:10.1111/j.1745-9125.1992.tb01093.x

Agnew, R. (1999). A General Strain Theory of Community Differences in Crime Rates. Journal of Research in Crime and Delinquency, 36(2), 123-155. doi:10.1177/0022427899036002001

Agnew, R. (2001). Building on the foundation of general strain theory: Specifying the types of strain most likely to lead to crime and delinquency. Journal of Research in Crime and Delinquency, 38(4), 319-361. doi:10.1177/0022427801038004001

Agnew, A., Broidy, R., \& Broidy, L. (1997). Gender and crime: a general strain theory perspective. Journal of Research in Crime and Delinquency 34(3), 275-306. doi: $10.1177 / 0022427897034003001$

Arbona, C. A. \& Coleman, M. N. (2008). Risk and resilience. In S. D. Brown \& R. W. Lent (Eds.), Handbook of counseling psychology, (4th ed.) (pp. 483-499). New York: Wiley.

(2012). Beat the Bullies: Tools You Can Use. Curriculum Review, 51(9), 10-10.

Bell, C. (2001). Cultivating Resiliency in youth. Journal of Adolescent Health, 29, 375381. doi:10.1016/51054-139x(01)00306-8 
Blum, J., Ireland, M., \& Blum., R. (2003). Gender differences in juvenile violence: A report from add health. Journal of Adolescent Health, 32, 234-240. doi:

\section{$10.1016 / \mathrm{S} 1054-139 \mathrm{X}(2) 00448-2$}

Bright, C. \& Johnson-Reid, M. (2008). Onset of juvenile court involvement: Exploring gender-specific associations with maltreatment and poverty. Children and Youth Services Review, 30, 914-927. doi.10.1016/j.childyouth.2007.11.015

Coholic, D. (2011). Exploring the feasibility and benefits of arts-based mindfulnessbased practices with young people in need: Aiming to improve aspects of selfawareness and resilience. Child and Youth Care Forum, 40(4), 303-317.

Cooley, M. R. (1995). Assessing community violence: The children's report of exposure to violence. Journal of the American Academy of Child \& Adolescent Psychiatry, 34(2), 201-208. doi:10.1097/00004583-199502000-00015

Crosnoe, R., Erickson, K., \& Dornbusch, S. (2002). Resiliency functions of family relationships and school factors on the deviant behavior of adolescent boys and girls. Youth \& Society, 33, 514-544. doi:10.1177/0044118X02033004002

Daigle, L., Cullen, F., \& Wright, J. (2007). Gender differences in the predictors of juvenile delinquency: Assessing the generality-specificity debate. Youth Violence and Juvenile Justice, 5, 254-286. doi:10.1177/1541204007301289

Ebrahim, A. (2012). The effect of cooperative learning strategies on elementary students' science achievement and social skills in Kuwait. International Jouranl of Science and Mathematics Education, 10(2), 293-314.7/1131652

Eisenberg, N., Guthrie, I. K., Fabes, R. A., Reiser, M., Murphy, B. C., Homgren, R. et al. (1997). The relations of regulation and emotionality to resiliency and competent 
social functioning in elementary school children. Child Development , 68, 295-311. doi:10.2307/1131851

Eith, C. (2005). Delinquency, school, and the social bond. New York, NY: LFB Scholarly Publishing.

Fabes, R. A., \& Eisenberg, N. (1992). Young children's coping with interpersonal anger. Child Development, 63, 116-128. doi:10.2307/1130906

Fagan, A., Van Horn, M., Hawkins, J., \& Arthur, M. (2007). Gender similarities and differences in the association between risk and resiliency factors and self-reported serious delinquency. Prevention Science, 8, 115-124. doi:10.1007/s11121-006$0062-1$

Farrington, D. (2005). Childhood origins of antisocial behavior. Clinical Psychology \& Psychotherapy, 12, 177-190. doi:10.1002/cpp.448

Fergusson, D. M. \& Lynskey, M. T. (1996). Adolescent resiliency to family adversity. Journal of Child Psychology and Psychiatry, 37(3), 281-292. doi:10.1111/j.14697610.1996.tb01405.x

Fergusson, D., Vitaro, F., Wanner, B. \& Brendgen, M. (2007). Resiliency and compensatory factors mitigating the influence of deviant friends on delinquent behaviors during early adolescence. Journal of Adolescence, 30, 33-50. doi:10.1016/j.adolescence.2005.05.007

Ganem, N. (2010). The role of negative emotion in general strain theory. Journal of Contemporary Criminal Justice, 26 (2), 167-185. doi:10.1177/1043986209359558 
Gardner, T., Dishioin, T., \& Connell, A. (2008). Adolescent self-regulation as resilience: Resistance to anti-social behavior within the deviant peer context. Journal of Abnormal Child Psychology, 36, 273-284. doi:10.1007/s10802-007-9176-6

Gottfredson, D. (2001). Schools and delinquency, New York, NY: Cambridge University Press. doi:10.1023/B:PREV.0000045359.41696.02

Hammack, P. L., Richards, M. H., Luo, Z., Edlynn, E. S. \& Roy, K. (2004). Social support factors as moderators of community violence exposure among inner-city African American young adolescents. Journal of Clinical Child and Adolescent Psychology, 33(3), 450-462. doi:10.1207/s15374424jccp3303_3

Hanlon, T., Bateman, R., Simon, B., O’Grady, K., \& Carswell, S. (2004). Antecedents and correlates of deviant activity in urban youth manifesting behavioral problems. The Journal of Primary Prevention, 24, 285-309. doi:10.1023/B:JOPP.0000018050.15852.d9

Hart, J., O’Toole, S., Price-Sharps, J., \& Shaffer, T. (2007). The risk and resiliency factors of violent juvenile offending: An examination of gender differences. Youth Violence and Juvenile Justice, 5, 367-384. doi:10.1177/1541204006297367

Harvey, M. (2007). Towards an ecological understanding of resilience in trauma survivors: Implications for theory research and practice. Journal of Aggression, Maltreatment \& Trauma, 14, 9-32. doi:10.1300/J146v14n01_02

Hawkins, J., Herrenkohl, T., Farrington, D., Brewer, D., Catalano, R., Harachi, T., \& Cothern, L. (2000). Juvenile justice bulletin: Predictors of youth violence. Washington D. C.: U. S. Department of Justice, Office of Justice programs, Office of Juvenile Justice and Delinquency Prevention. 
Haynie, D., Petts, R., Maimon, D., \& Pequero, A. (2009). Exposure to violence in adolescence and precocious role exits. Journal of Youth and Adolescence, 38, 269286. doi:10.1007/s10964-008-9343-2

Herronkohl, T., Tajima, E., Whitney, S., \& Huang, B. (2005). Protection against antisocial behavior in children exposed to physically abusive discipline. Journal of Adolescent Health, 36, 457-465. doi:10.1016/j.jadohealth.2003.09.025

Hirschi, T. (1969). The causes of delinquency. Berkeley: The University of California Press.

Howell, J. (1998). Youth gangs: An overview. Washington D. C.: U.S. Department of Justice, Office of Justice Programs, Office of Juvenile Justice and Delinquency Prevention.

Jessor, R., Van Den Bos, J., Vanderryn, J., Costa, F., \& Turbin, M. (1995). Resiliency factors in adolescent problem behavior: Moderator effects and developmental change. Developmental Psychology, 31, 923-933. doi:10.1037//0012-1649.31.6.923

Karcher, M. J. (2001). The Hemmingway: Measure of adolescent connectedness: Validation Studies. Retrieved from ERIC database. (ED477969).

Karcher, M. (2003). The Hemmingway-measure of adolescent connectedness: A manual for interpretation and scoring. Unpublished manuscript, University of Texas at San Antonio.

Karcher, M. (2005). The effects of developmental mentoring and high school mentors' attendance on their younger mentees' self-esteem, social skills, and connectedness. Psychology in the Schools, 42(1), 65-77. doi:10.1002/pits.20025 
Karcher, M. (2009). Increases in academic connectedness and self-esteem among high school students who serve as cross-age peer mentors. Professional School Counseling, 12(4), 292-299. doi:10.5330/PSC.n.2010-12.292

Karcher, M. \& Lindwall, J. (2003). Social interest, connectedness, and challenging experiences: What makes high school mentors persist? Journal of Individual Psychology, 59(3), 293-315.

Karcher, M. \& Sass, D. (2010). A multicultural assessment of adolescent connectedness: Testing measurement invariance across gender and ethnicity. Journal of Counseling Psychology, 57(3), 274-289. doi:10.1037/a0019357

Karcher, M., Holcomb, M., \& Zambrano, E. (2008). Measuring and evaluating adolescent connectedness. In H. L. Coleman \& C. Yeh (Eds.) Handbook of school counseling (pp. 651-672). London: Routledge.

Kazdin, A. (1987). Treatment of antisocial behavior in children: Current status and future directions. Psychological Bulletin, 102, 187-203. doi:10.1037//00332909.102.2.187

Krantz, P. (2005). Standards-schmandards: Methods for measuring test readability. www.standards-schmandards.com/exhibits/rix/index.php

Kelley, B., Thornberry, T., \& Smith, C. (1997). Juvenile Justice Bulletin: In the wake of childhood maltreatment. Washington D.C.: U. S. Department of Justice, Office of Justice Programs, Office of Juvenile Justice and Delinquency Prevention.

Lambert, S., Ialongo, N., Boyd, R., \& Cooley, M. (2005). Risk factors for community violence exposure in adolescence. American Journal of Community Psychology, 36, 29-48. doi: 10.1007/s10464-005-6231-8 
Leiss, D., Pekrun, R. Blum, W., Muller,M., \& Messner, R. (2012). Teaching methods for modeling problems and students' task-specific enjoyment, value, interest, and selfefficacy expectations. Education Studies in Mathaematics, 79(2), 215-237.

Loeber, R. \& Stouthamer-Loeber, M. (1986). Family factors as correlates of juvenile conduct problems and delinquency. In M. Tony \& N. Morris (Eds.), Crime and justice: An annual review of research (pp. 29-149). Chicago, IL: University of Chicago Press.

Lowe, N., May, D., \& Elrod, P. (2008). Theoretical predictors of delinquency among public school students in a mid-southern state: The roles of context and gender. Youth Violence and Juvenile Justice, 6, 343-362. doi:10.1177/1541204008320259

Luthar, S. (1991). Vulnerability and resilience: A study of high-risk adolescents. Child Development, 600, 600-616. doi:10.2307/1131134

Margolin, G. \& Gordis, B. (2000). The effects of family and community violence on children. Annual Review of Psychology, 51, 445-479.

doi:10.1146/annurev.psych.51.1.445

Markstrom, C., Marshall, S., \& Tyron, R. (2000). Resiliency, social support, and coping in rural low-income Appalachian adolescents from two racial groups. Journal of Adolescence, 23, 693-703. doi:10.1006/jado.2000.0353

Masten, A. (1987). Resilience in development: Implications of the study of successful adaptation for developmental psychopathology. In C. Cicchetti (Ed.), The emergence of a discipline: Rochester symposium on developmental psychopathology (pp. 261294). Hillsdale, NJ: Lawrence Erlbaum. 
Masten, A. S. \& Coatsworth, J. D. (1998). The development of competence in favorable and unfavorable environments. American Psychologist, 53(2), 205-220. doi:10.1037//0003-066X.53.2.205

McGee, Z. (2002). Community violence and adolescent development: An examination of risk and resiliency factors among African American youth. Journal of Contemporary Criminal Justice, 19, 293-314. doi:10.1177/1043986203254527

McShane, M. \& Williams, III, F. (Eds.) (2007). Youth violence and delinquency: Monster and myths, Westport, Ct.: Praeger.

McKnight, L. \& Loper, B. (2002). The effect of risk and resilience factors on the prediction of delinquency in adolescent girls. School Psychology International, 23, 186-198. doi:10.1177/01434302023002744

Menard, S. (2002). Youth violence research bulletin: Short- and long-term consequences of adolescent victimization. Washington D. C.: U.S. Department of Justice, Office of Justice Programs, Office of Juvenile Justice and Delinquency Prevention.

Moon, B., Blurton, D., \& Mccluskey, J. D. (2008). General Strain Theory and Delinquency: Focusing on the Influences of Key Strain Characteristics on Delinquency. Crime \& Delinquency, 54(4), 582-613.

doi:10.1177/0011128707301627

Ostaszewski, K. \& Zimmerman, M. (2006). The effects of cumulative risks and promotive factors on urban adolescent alcohol and other drug use: A longitudinal study of resilience. American Journal of Community psychology, 38, 237-249. doi:10.1007/s10464-006-9076-X 
Ozer, E. \& Weinstein, R. (2004). Urban adolescents' exposure to community violence: The role of support, school safety, and social constraints in a school based sample of boys and girls. Journal of Clinical Child and Adolescent Psychology, 33, 463-476. doi:10.1207/s15374424jccp3303_4

Perkins, D. and Jones, K. (2004). Risk behaviors \& resiliency within physically abused adolescents. Child Abuse \& Neglect, 28, 547-563. doi:10.1016/j.chiabu.2003.12.001

Prince-Embury, S., (2005). Resiliency Scale for adolescents: A profile of personal strengths, San Antonio, TX: Pearson Education, Inc.

Prince-Embury, S., \& Courville, T. (2008). Comparison of one-, two-, and three-factor models of personal resiliency using the Resiliency Scales for Children and Adolescents. Canadian Journal of School Psychology, 23, 11-25. doi: 10.1177/0829573508316589582-613.

Prince-Embury, S. (2007). Manual for the Resiliency Scales for Children and Adolescents: A profile of personal strengths. Minneapolis, MN: Pearson, Inc. Prince-Embury, S. (2008). The resiliency scales for children and adolescents, psychological symptoms, and clinical status in adolescents. Canadian Journal of School Psychology, 23, 41-56. doi:10.1177/0829573508316592

Rak, C. \& Patterson, L. (1996). Promoting resilience in at-risk children. Journal of Counseling \& Development, 74, 368-373.

Reiss, D. (Ed.). (1993). Children and violence. New York: Guilford Press.

Roberts, A. (Ed.). (2004). Juvenile justice sourcebook: Past, present, and future. oxford, NY: Oxford University Press. 
Smokowski, P., Mann, E., Reynolds, A., \& Fraser, M. (2004). Childhood risk and resiliency factors and late adolescent adjustment in inner city minority youth. Children and Youth Services Review, 26, 63-91. doi:10.1016/j.childyouth.2003.11.003

Snyder, H. N. (2007). Not this time: A response to the warnings of the juvenile super predator. Corrections Today, 69(2), 116-117.

Solberg, S., Carlstrom, A., Howard, K., \& Jones, J. (2007). Classifying at risk high school youth: The influence of community violence and protective factors on academic and health outcomes. Career Development Quarterly, 55, 313-327.

Spence, S., De Young, A, Toon, C. \& Bond, S. (2009). Longitudinal examination of the associations between emotional dysregulation, coping responses to peer provocation, and victimization in children. Australian Journal of Psychology, 61, 145-155. doi: $10.1080 / 00049530802259076$

Sullivan, T., Farrell, A., Kliewer, W., Vulin-Reynolds, M., \& Valois, R. (2007). Exposure to violence in early adolescence. Journal of Early Adolescence, 27, 296323. doi:10.1177/0272431607302008

Sutherland, E. (1924). Principles of criminology. Chicago: University of Chicago Press.

Tabachnick, B. G., \& Fidell, L. S. (2001). Using multivariate statistics (4th ed.). Boston, MA: Allyn and Bacon.

Thompson, B. (2000). Canonical Correlation Analysis. In L. G. Grimm \& P. R. Yarnold (Eds.). Reading and understanding more multivariate statistics (pp. 285-316). Washington, D.C.: American Psychological Association. 
Thorne, K., Kohut, C., \& Prince-Embury, S. (2007). Resiliency Scales for Children and Adolescents: A profile of personal strengths. San Antonio, TX: Harcourt Assessment, Inc. doi:10.1177/0829573507305520

Travis, J. (1996). Research preview: The cycle of violence revisited. Washington D.C.: Office of Justice Programs, National Institute of Justice.

Welsh, B. (1999). Delinquency prevention using family-based interventions. Child and Society, 13(4), 287-303.

Wolkow, K., \& Ferguson, H. (2001). Community factors in the development of resiliency: Considerations and future directions. Community Mental Health Journal, 37, 489-498. doi:10.1023/A:1017574028567

Yoshikawa, H. (1994). Prevention as cumulative protection: Effects of early family support and education on chronic delinquency and its risks. Psychological Bulletin, 115, 28-54. doi:10.1037//0033-2909.115.1.28 
APPENDICES 


\section{APPENDIX A}

INSTITUTIONAL REVIEW BOARD APPROVAL LETTER 


\title{
Cleveland State

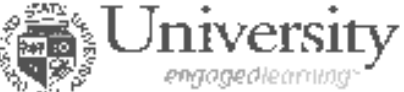

\section{Memorandum}

\author{
Institutional Review Boutrd \\ Toi Donna Schultheiss \\ CAGAL \\ Frant

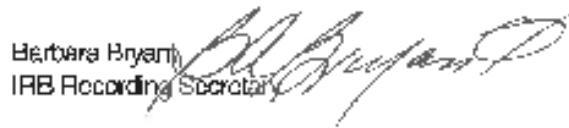 \\ Date: June 29,7012 \\ Re; Results of IRB Tevew of your project number: \#29426-5CH-HS \\ Co-irnesiligaltor: Narryy Ghiali \\ Entitied: Resiliency in youth who have been exposed to vlolence
}

The IRE has reviewed and approwed yout asp Icalion for the above mamed project, under the category noted bolow. Approval for use of F.Liman subjects in this research is for one ycar froth loday. If your stuxty extends beyond this approval period, you must contact this offeo to initigfe an

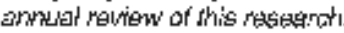

By accepting this decision: you agrse to notify the IRB of: (1) ary additions to or ciangos in procedures for 'your study that modily the subjects' rigk in any way. and (2) any events that effect that sarely or well-being of subjecks. Notity the IAB of any revigions to the protoxol: including the addition of researchers, prior to implementation.

Thank you tor your efforts to maintain compliance with the federal regulations for the protection of human subjocts.

\section{Approval Category:}

Dade: November 21, 2011

X . Full Board: Regular IRB

cc: Project file 
APPENDIX B

INFORMED CONSENT FORM 


\section{Informed Consent to Participate in a Research Study}

Project Title: Resiliency in Youth Who Have Been Exposed to Violence

Dear Parent or Guardian:

My name is Nancy Ghali and I am a doctoral student at Cleveland State University. I am requesting your permission to allow your son or daughter to participate in a study exploring those factors which seem to protect youth from the harmful effects of violence. Your child will be asked to complete a total of 5 questionnaires including a measure of his or her exposure to violence, his or her ability to cope with difficult situations, his or her connection with parents, teachers, and friends, and a questionnaire providing background information such as age and gender. All questionnaires will be administered during a designated class period and will take no more than 50 minutes to complete. Students who participate in the study will be placed in a drawing for a chance to win one of six gift cards from iTunes ( 2 valued at $\$ 10$ each), K-Mart ( 2 valued at \$25 each), and McDonalds (2 valued at \$5 each). By participating in the study your child will be providing information which can help other students who may be at risk due to exposure to violence. However, there is no direct benefit for your child outside of the potential to win one of the listed gift cards.

The questionnaires will remain completely anonymous and your child will never be asked to write their name on any of the surveys or questionnaires. The information gathered will be used for research purposes only and will not be linked to your child in any way.

The risks for participating in the study include discomfort from thinking about violence and negative feelings from remembering any possible exposure to violence. One measure assesses for the students exposure to violence and includes items such as "Have you ever seen a stranger being shot or stabbed?" and "Have you ever been told about a stranger being killed?" There is also a demographic questionnaire which asks students to report "Have you ever used a weapon in a fight?" and "How often do you use drugs and alcohol?' Students who experience discomfort will be referred to the guidance counselor for further assistance.

Consent to participate in this study is completely voluntary and you or your child can choose to withdraw from the study at any time with no penalty. Students may also choose not to answer any of the questions at any time during the study.

Findings from this study will provide important information on resiliency and how to reduce the effects of exposure to violence. Furthermore, those findings can provide crucial information for developing effective prevention and intervention programs for youth who are at risk.

Please feel free to contact me at (440) 773-8883 or email me at n.ghali@ csuohio.edu if you have any questions or concerns about this study. You can also contact my faculty advisor, Dr. Donna Schultheiss, at (216) 687-5083 or email her at d.schultheiss@ csuohio.edu.

\section{If you have any questions about your child's rights as a research subject you can contact the Cleveland State University Institutional Review Board at (216) 687-3630.}

If you agree to allow your child to participate in the study please sign one copy of the informed consent form and have your child return it to his or her teacher. The other copy is for your records. Your child will also need to sign the child assent form and return it with the informed consent form.

Thank you for your consideration for this important study.

\author{
Nancy Ghali \\ Student Researcher
}

Parent/Guardian (Print Name)

\author{
Parent/Guardian Signature Date
}

Student Name 
APPENDIX C

ASSENT FORM 


\section{Informed Student Assent to Participate in a Research Study}

Project Title: Resiliency in Youth Who Have Been Exposed to Violence

Dear Student:

My name is Nancy Ghali and I am a student at Cleveland State University. I am asking you to participate in a study about things that protect youth who have been exposed to violence. If you agree to participate you will be asked to complete a total of 5 surveys asking about your exposure to violence, your ability to cope with difficult situations, your relationship with your parents, teachers, and friends, and a questionnaire providing background information such as your age and gender. The surveys will be administered during class and will not take more than 50 minutes to complete. Students who participate in the study will be placed in a drawing for a chance to win one of six gift cards from iTunes (2 valued at \$10 each), K-Mart (2 valued at \$25 each), and McDonalds (2 valued at \$5 each).

You will not be asked to place your name on any of the surveys and there will be no way to identify which one is yours. The answers you provide will be used for research purposes only and your responses will not be shared with anyone.

There is potential risk for participating in the study including being uncomfortable thinking about violence and possible negative feelings from remembering violent events. If you feel any discomfort you will be able to talk with your guidance counselor about these feelings.

Agreeing to participate in this study is completely voluntary and you can choose to withdraw from the study at any time with no penalty. You may also choose not to answer any question at any point during the study.

The results from this study will provide important information on how to help youth cope with exposure to violence and in developing programs to help youth who are at risk for being exposed to violence.

Please feel free to contact me at (440) 773-8883 or email me at n.ghali@ csuohio.edu if you have any questions or concerns about this study. You can also contact my faculty advisor, Dr. Donna Schultheiss, at (216) 687-5083 or email her at d.schultheiss@ csuohio.edu.

If you have any questions about your rights as a research subject you can contact the Cleveland State University Institutional Review Board at (216) 687-3630.

Student (Print Name)

Student Signature

Date

Witness

Date 


\section{APPENDIX D}

DEMOGRAPHIC QUESTIONNAIRE 


\section{DEMOGRAPHIC QUESTIONNAIRE}

1. What grade are you in? $\quad 9^{\text {th }} \square \quad 10^{\text {th }} \square \quad 11^{\text {th }} \square \quad 12^{\text {th }}$

2. What is your current Grade Point Average?

3. How old are you?

14

15

16

17

18

19

4. What is your gender? Male $\square$ Female

5. What is your Racial/Ethnic background?

$\begin{array}{ccr}\text { Caucasian } \square \quad \text { African American } \square \quad \text { Hispanic } \\ \text { Asian } \square \quad \text { American Indian } \square & \text { Other } \square\end{array}$

6. Are your parents, caregivers, or guardians:

Married $\square \quad$ Separated $\square \quad$ Divorced $\square \quad$ Never Married

7. How many adults live in your house $(18$ years old +$)$ ?

8. How many children live in your house ( $<18$ years old)?

9. Have you ever been arrested? Yes $\square$ No $\square$

If yes, for what?

10. Have you ever been suspended or expelled from school? Yes

No

If yes, how many times have you been suspended?

Why were you suspended?

11. How often do you use drugs or alcohol?

Every Day $\square \quad$ 1-2 times per week $\square \quad$ 3-4 times per week $\square \quad$ 4-6 times per week

1-2 times per month $\square \quad$ Hardly Ever $\square \quad$ Never $\square$

12. How many times have you been in a fight?

13. If yes, have you ever used a weapon in a fight? $\quad$ Yes $\square$ No

14. Have you ever seriously hurt someone in a fight? Yes $\square$ No 


\author{
APPENDIX E \\ YOUTH SELF REPORT \\ (C) Copyright 1991 T. M. Achenbach \\ Available From: \\ Department of Psychiatry \\ University of Vermont \\ 1 S. Prospect St., Burlington, VT 05401 \\ www.aseba.org
}




\section{APPENDIX F}

HEMMINGWAY MEASURE OF ADOLESCENT CONNECTEDNESS 


\section{Hemmingway Measure of Adolescent Connectedness}

Instructions: First tell us, do you have any brothers or sisters? No Yes (circle one). Next, please use this survey to tell us about yourself. Read each statement. Circle the number that best describes how true that statement is for you or how much you agree with it. If a statement is unclear to you, ask for an explanation. If it is still unclear, put a "?"

How TRUE about you is each sentence?

Not at all $=1$, not really true $=2$, sort of true $=3$, true $=4$, very true $=5$.

1. Spending time with friends is not so important to me. $\quad 12345$

2. I care what my teachers think of me.

3. I have friends I'm really close to and trust completely.

4. It is important that my parents trust me.

5. I do not get along with some of my teachers.

6. Spending time with my friends is a big part of my life.

123345

7. I enjoy spending time with my parents.

$\begin{array}{lllll}1 & 2 & 3 & 4 & 5\end{array}$

8. I want to be respected by my teachers.

9. My friends and I talk openly with each other about personal things.

10. My parents and I disagree about many things.

11. I try to get along with my teachers.

12. I spend as much time as I can with my friends.

13. My parents and I get along well. 


\section{APPENDIX G}

CHILDREN'S REPORT OF EXPOSURE TO VIOLENCE-REVISED 


\section{Children's Report of Exposure to Violence-Revised}

Directions: These questions ask about violence. Violence is when somebody attacks or hurts another person. These questions are about things that may have happened at home, school, or in your neighborhood. Make sure you answer each question by circling the one that is most true for you. Raise your hand if you do not understand a question.

- Some questions ask about violence that you heard happened to someone else. This means that somebody told you this happened in real life.

- Other questions ask about violence that you saw happening to someone else. This means that you were there and saw it happening in real life.

- And more questions ask about violence that happened to you. This means that it happened to you in real life.

Sample: Here is a practice question:

0 = No, Never $1=$ One Time $2=$ A Few Times $3=$ Many Times $4=$ Everyday

$\begin{array}{lrlll}\text { Have you ever eaten ice-cream? } & 1 & 2 & 3 & 4\end{array}$

$\begin{array}{lllll}\text { In the last year, how many times have you eaten ice-cream? } & 1 & 2 & 3 & 4\end{array}$

These questions are about violence against a stranger.

A stranger is somebody you don't know.

These questions ask about a stranger being beaten up.

Beaten up means being slapped, kicked, bitten, hit, or punched

so that they were hurt badly.

1a. Have you ever been told that a stranger was beaten up?

$\begin{array}{llll}1 & 2 & 3 & 4\end{array}$

1b. In the last year how many times have you been told a

$\begin{array}{llll}1 & 2 & 3 & 4\end{array}$ stranger was beaten up?

2a. Have you ever seen a stranger being beat up?

$\begin{array}{llll}1 & 2 & 3 & 4\end{array}$

2b. In the last year, how many times have you seen a stranger being

$\begin{array}{llll}1 & 2 & 3 & 4\end{array}$ beaten up?

3a. Have you ever been told that a stranger was chased or

$\begin{array}{llll}1 & 2 & 3 & 4\end{array}$ seriously threatened?

$0=$ No, Never $1=$ One Time $2=$ A Few Times $3=$ Many Times $4=$ Everyday

3b. In the last year, how many times have you been told

$\begin{array}{llll}1 & 2 & 3 & 4\end{array}$ a stranger was chased or threatened? 
4a. Have you ever seen a stranger being chased or seriously threatened?

4b. In the last year, how many times have you seen a stranger being chased or threatened?

These questions ask about a stranger being robbed or mugged.

Robbed or mugged means somebody took their things from them by force.

5a. Have you ever been told that a stranger was robbed or mugged?

$\begin{array}{llll}1 & 2 & 3 & 4\end{array}$

5b. In the last year, how many times have you been told a stranger

$\begin{array}{llll}1 & 2 & 3 & 4\end{array}$ was robbed or mugged?

6a. Have you ever seen a stranger being robbed or mugged?

$\begin{array}{llll}1 & 2 & 3 & 4\end{array}$

6b. In the last year, how many times have you seen a stranger being

$\begin{array}{llll}1 & 2 & 3 & 4\end{array}$ robbed or mugged?

These questions ask about a stranger being shot or stabbed.

Shot or stabbed means somebody hit them with a bullet from a gun or badly hurt them with a knife.

7a. Have you ever been told that a stranger was shot or stabbed? $\quad 1 \quad 2 \quad 3 \quad 4$

7b. In the last year, how many times have you been told a stranger $\quad \begin{array}{llll}1 & 2 & 3 & 4\end{array}$ was shot or stabbed?

8a. Have you ever seen a stranger being shot or stabbed?

$\begin{array}{llll}1 & 2 & 3 & 4\end{array}$

$8 \mathrm{~b}$. In the last year, how many times have you seen a stranger

$123 \quad 3 \quad 4$ being shot or stabbed?

These questions ask about a stranger being killed.

Being killed means they were shot, stabbed, or beaten to death.

9a. Have you ever been told about a stranger being killed?

$\begin{array}{llll}1 & 2 & 3 & 4\end{array}$

9b. In the last year, how many times have you been told a

$\begin{array}{llll}1 & 2 & 3 & 4\end{array}$ stranger was killed? 
0 $=$ No, Never $1=$ One Time $2=$ A Few Times $3=$ Many Times $4=$ Everyday

10a. Have you ever seen a stranger being killed? $\quad \begin{array}{llll}1 & 2 & 3 & 4\end{array}$

10b. In the last year, how many times have you seen a stranger $\quad \begin{array}{llll}1 & 2 & 3 & 4\end{array}$ being killed?

These questions ask about violence against familiar people.

Familiar people are people you know like friends, classmates, relatives, cousins, sisters, brothers, and parents.

These questions ask about anyone you know being beaten up.

Beaten up means being slapped, kicked, bitten, hit, or punched so that they were badly hurt.

11a. Have you ever been told that somebody you know was beaten up? $\begin{array}{lllll}1 & 2 & 3 & 4\end{array}$

11b. In the last year, how many times have you been told somebody $\quad \begin{array}{llll}1 & 2 & 3 & 4\end{array}$ you know was beaten up?

12a. Have you ever seen somebody you know being beaten up? $\quad 1 \quad 2 \quad 3 \quad 4$

12b. In the last year, how many times have you seen somebody $\quad \begin{array}{llll}1 & 2 & 3 & 4\end{array}$ you know being beaten up?

These questions ask about anyone you know being chased or threatened.

Chased or threatened means having somebody come after or want to badly or seriously hurt their bodies.

13a. Have you ever been told that somebody you know was $\quad \begin{array}{llll}1 & 2 & 3 & 4\end{array}$ chased or seriously threatened?

13b. In the last year, how many times have you been told $\quad \begin{array}{llll}1 & 2 & 3 & 4\end{array}$ somebody you know was chased or threatened?

14a. Have you ever seen somebody you know being chased $\quad \begin{array}{llll}1 & 2 & 3 & 4\end{array}$ or seriously threatened?

14b. In the last year, how many times have you seen somebody $\quad \begin{array}{lllll}1 & 2 & 3 & 4\end{array}$ you know being chased or threatened? 
0 = No, Never $1=$ One Time $2=$ A Few Times $3=$ Many Times $4=$ Everyday

These questions ask about anyone you know being robbed or mugged.

Robbed or mugged means somebody took their things from them by force.

15a. Have you ever been told that somebody you know $\quad \begin{array}{llll}1 & 2 & 3\end{array}$ was robbed or mugged?

15b. In the last year, how many times have you been told $\quad \begin{array}{llll}1 & 2 & 3 & 4\end{array}$ somebody you know was robbed or mugged?

16a. Have you ever seen somebody you know being robbed $\quad \begin{array}{llll}1 & 2 & 3 & 4\end{array}$ or mugged?

16b. In the last year, how many times have you seen somebody $\quad \begin{array}{llll}1 & 2 & 3 & 4\end{array}$ you know being robbed or mugged?

These questions ask about anyone you know being shot or stabbed.

Shot or stabbed means somebody hit them with a bullet from a gun or baldy hurt them with a knife.

17a. Have you ever been told that somebody you know was $\quad \begin{array}{llll}1 & 2 & 3 & 4\end{array}$ shot or stabbed?

17b. In the last year, how many times have you been told somebody $\quad \begin{array}{lllll}1 & 2 & 3 & 4\end{array}$ you know was shot or stabbed?

18a. Have you ever seen somebody you know being shot or stabbed? $\quad \begin{array}{llll}1 & 2 & 3 & 4\end{array}$

18b. In the last year, how many times have you seen somebody you $\quad \begin{array}{llll}1 & 2 & 3 & 4\end{array}$ know being shot or stabbed?

These questions ask about anyone you know being killed.

Being killed means they were shot, stabbed, or beaten to death.

19a. Have you ever been told that somebody you know was killed? $\quad \begin{array}{llll}1 & 2 & 3 & 4\end{array}$

19b. In the last year, how many times have you been told somebody $\quad \begin{array}{llll}1 & 2 & 3 & 4\end{array}$ you know was killed?

20a. Have you ever seen somebody you know being killed? $\quad \begin{array}{lllll}1 & 2 & 3 & 4\end{array}$

20b. In the last year, how many times have you seen somebody you $\quad \begin{array}{llll}1 & 2 & 3\end{array}$ know being killed? 
0 = No, Never $1=$ One Time $2=$ A Few Times $3=$ Many Times $4=$ Everyday These questions ask about violence that has happened to you.

Being beaten up means being slapped, kicked, bitten, hit or punched so that you were badly hurt.

21a. Have you ever been beaten up?

$\begin{array}{llll}1 & 2 & 3 & 4\end{array}$

21b. In the last year, how many times have you been beaten up?

$\begin{array}{llll}1 & 2 & 3 & 4\end{array}$

Being chased or threatened means having somebody come after or want to badly or seriously hurt your body.

22a. Have you ever been chases or threatened?

$\begin{array}{llll}1 & 2 & 3 & 4\end{array}$

22b. In the last year, How many times have you been chased

$\begin{array}{llll}1 & 2 & 3 & 4\end{array}$ or threatened?

Being robbed or mugged means somebody took your things from you by force.

23a. Have you ever been robbed or mugged?

$123 \quad 3 \quad 4$

$23 \mathrm{~b}$. In the last year, how many times have you been robbed

$\begin{array}{llll}1 & 2 & 3 & 4\end{array}$ or mugged?

Being shot or stabbed means having somebody hit you with a bullet from a gun or badly hurt you with a knife.

24a. Have you ever been shot or stabbed?

$\begin{array}{llll}1 & 2 & 3 & 4\end{array}$

24b. In the last year, how many times have you been shot or stabbed? $\quad \begin{array}{llll}1 & 2 & 3 & 4\end{array}$ 


\section{APPENDIX H}

Resiliency Scale for Adolescents: A Profile of Personal Strengths

\section{Copyright 2005 S. Prince-Embury}

Available From:

Pearson Education, Inc.

San Antonio, TX 